\title{
Particulate allergens potentiate allergic asthma in mice through sustained IgE-mediated mast cell activation
}

\author{
Cong Jin, ${ }^{1}$ Christopher P. Shelburne, ${ }^{2}$ Guojie Li, ${ }^{2}$ Kristina J. Riebe,, ${ }^{3}$ \\ Gregory D. Sempowski, ${ }^{3}$ W. Michael Foster, ${ }^{3}$ and Soman N. Abraham 1,2,4,5 \\ 1Department of Molecular Genetics and Microbiology, ${ }^{2}$ Department of Pathology, ${ }^{3}$ Department of Medicine, and ${ }^{4}$ Department of Immunology, \\ Duke University Medical Center, Durham, North Carolina, USA. ${ }^{5}$ Program in Emerging Infectious Diseases, \\ Duke National University of Singapore Graduate Medical School, Singapore.
}

\begin{abstract}
Allergic asthma is characterized by airway hyperresponsiveness, inflammation, and a cellular infiltrate dominated by eosinophils. Numerous epidemiological studies have related the exacerbation of allergic asthma with an increase in ambient inhalable particulate matter from air pollutants. This is because inhalable particles efficiently deliver airborne allergens deep into the airways, where they can aggravate allergic asthma symptoms. However, the cellular mechanisms by which inhalable particulate allergens (pAgs) potentiate asthmatic symptoms remain unknown, in part because most in vivo and in vitro studies exploring the pathogenesis of allergic asthma use soluble allergens (sAgs). Using a mouse model of allergic asthma, we found that, compared with their sAg counterparts, pAgs triggered markedly heightened pulmonary eosinophilia in allergen-sensitized mice. Mast cells (MCs) were implicated in this divergent response, as the differences in airway inflammatory responses provoked by the physical nature of the allergens were attenuated in MC-deficient mice. The pAgs were found to mediate $\mathrm{MC}$-dependent responses by enhancing retention of $\mathrm{pAg} / \mathrm{IgE} / \mathrm{Fc} \varepsilon \mathrm{RI}$ complexes within lipid raft-enriched, $\mathrm{CD}^{+}{ }^{+}$endocytic compartments, which prolonged IgE/FceRI-initiated signaling and resulted in heightened cytokine responses. These results reveal how the physical attributes of allergens can co-opt MC endocytic circuitry and signaling responses to aggravate pathological responses of allergic asthma in mice.
\end{abstract}

\section{Introduction}

Allergic asthma is a pathological condition of the airways characterized by airway hyperresponsiveness (AHR), inflammation, and a cellular infiltrate dominated by eosinophils $(1,2)$. During the past decade, the incidence and severity of allergic asthma has grown sharply (3). Approximately 300 million people worldwide suffer from asthma, and its prevalence increases by $50 \%$ every decade (3). The global economic cost of treating asthma now exceeds the total cost of treating HIV/AIDS and tuberculosis combined (3). Many epidemiological studies have revealed a strong correlation between increased incidence of asthma and increasing levels of ambient inhalable particulate matter (PM; refs. 4-6), attributable in part to progressive urbanization and climate change $(3,7)$. Ambient inhalable PM is typically less than $10 \mu \mathrm{m}$ in size and is commonly composed of household and traffic dust, construction debris, soot particles from gaseous industrial waste, and diesel exhaust particles from vehicle emissions. Because of their intrinsic electrostatic properties and porous surfaces, these particulates are extremely "sticky" and readily adhere to free airborne allergens released from animal dander, dust mites, mold, and pollen (7-9). Ambient inhalable PM can thereby serve as an efficient allergen delivery device, enabling the trafficking of allergens in concentrated form deep into the airways and triggering severe clinical outcomes $(9,10)$.

Because natural allergens gain access to the airways in particulate form, and growing epidemiological data correlate the exacerbation of allergic asthma with increasing exposure to airborne particles, we

Conflict of interest: The authors have declared that no conflict of interest exists. Citation for this article: J Clin Invest. 2011;121(3):941-955. doi:10.1172/JCI43584 hypothesized that the physical nature of particulate allergens might be crucial to the aggravation of allergic asthma symptoms. However, much of our current knowledge about the pathogenesis of allergic asthma originates from studies that examined the nature and magnitude of host responses to soluble allergens (sAgs) in sensitized animals. Little is known about the pathological responses evoked by allergens in particulate form, particularly allergens that adhere to particulate cores. Therefore, we compared airway pathological responses to conventional sAgs and to allergens covalently conjugated to the surface of $1 \mu \mathrm{m}$ polystyrene particles, forming particulate allergens (pAgs), in sensitized mice. This paired allergen model, in which the physical nature is the only difference between sAgs and pAgs, allows us to exclusively examine the role of pAgs in triggering allergic asthma symptoms. Importantly, this model allowed us to avoid the problems associated with the variable composition and intrinsic bioactivity of collected ambient particulate allergens.

In the present study, we reveal that pAgs provoked more potent pulmonary allergic responses than did identical amounts of sAgs in sensitized mice. Moreover, we found that mast cells (MCs) modulated this differential outcome based on their ability to discriminate between the physical nature of these allergens. We further found that the differential response of MCs to pAgs and sAgs was caused by MC internalization of pAgs into lipid raft-enriched, $\mathrm{CD}^{2} 3^{+}$intracellular compartments, where $\mathrm{pAg} / \mathrm{IgE} / \mathrm{FcERI}$ complexes sustained their association with the lipid raft signaling platform. Consequently, this elongated harboring of pAgs in distinct endocytic MC compartments led to prolonged FceRI signaling and elevated de novo synthesis of MC proinflammatory mediators, ultimately resulting in exacerbated host allergic responses. 
A

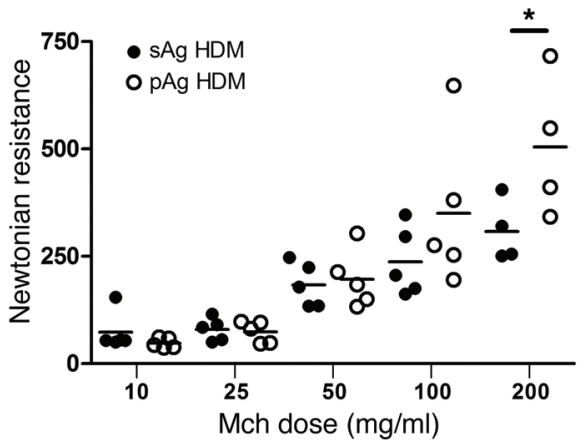

B

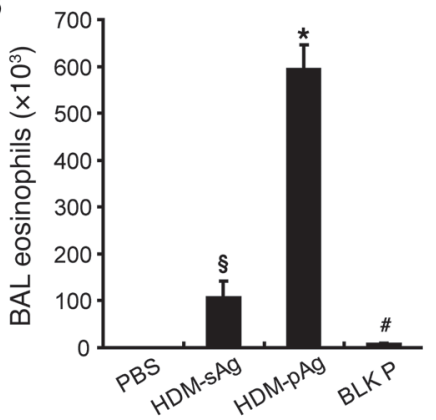

C

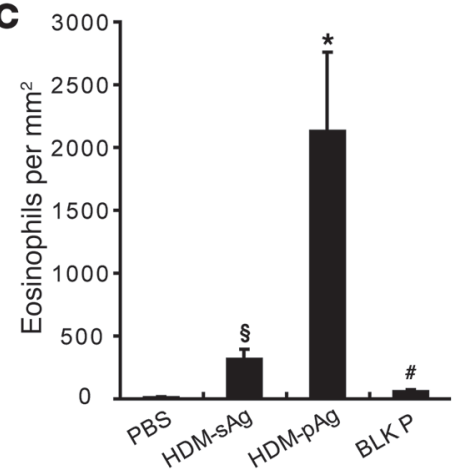

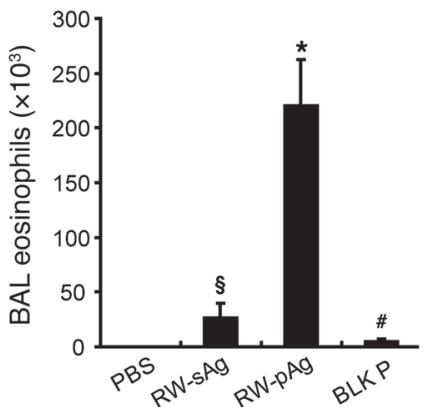

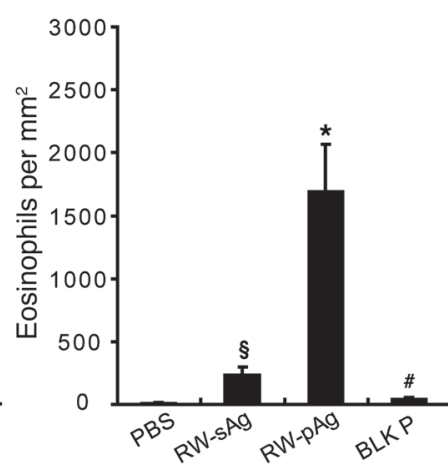

D

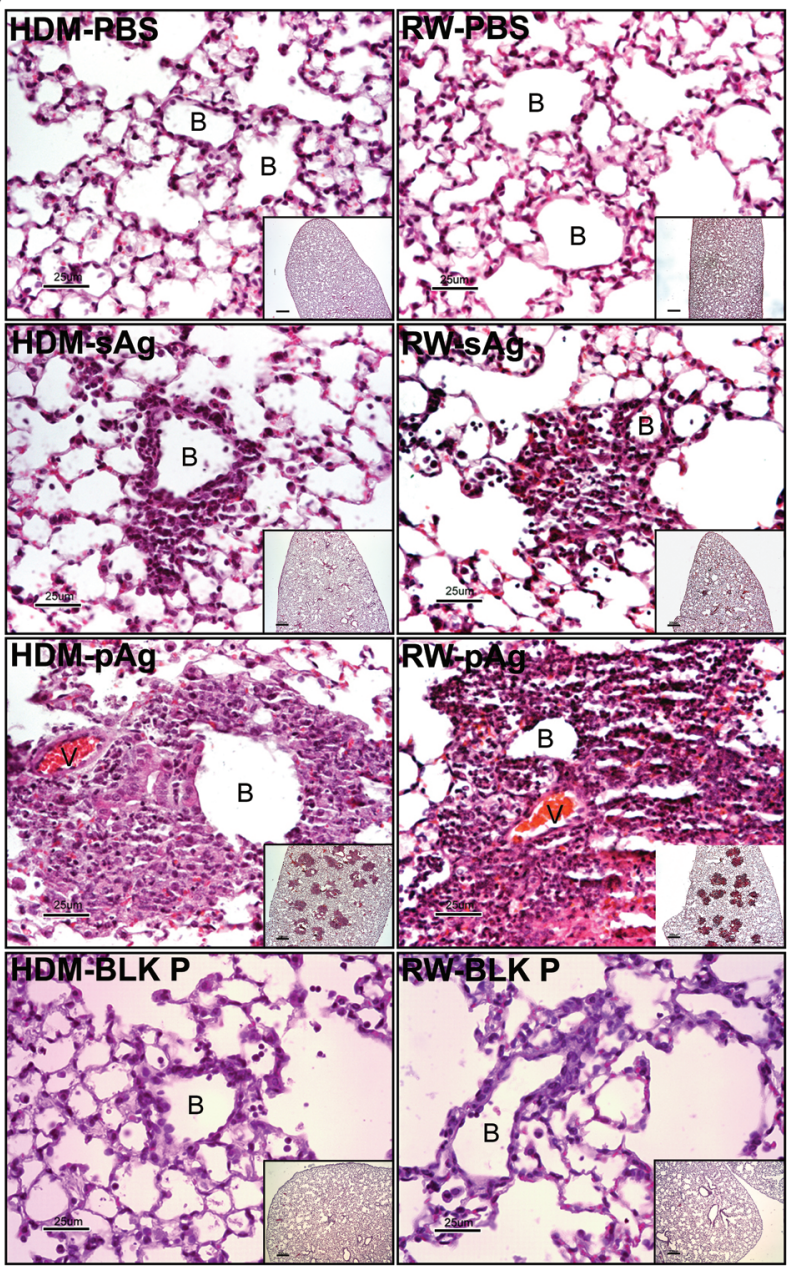

Figure 1

pAgs induce heightened airway allergic responses compared with sAgs. (A) House dust mite-sensitized mice were challenged with HDM in sAg or pAg form. AHR was measured 24 hours after challenge. (B-C) Allergen-sensitized mice were challenged with HDM or RW in sAg or pAg form, saline or unconjugated particles, 48 hours after challenge. (B) BAL eosinophil influx and (C) lung histology were analyzed. For panels B-C, $n=5$. ${ }^{*} P<0.05$, pAg versus $\mathrm{sAg} ;{ } \$ P<0.01$, sAg versus PBS; ${ }^{*} P<0.01$, pAg versus unconjugated particles. (D) H\&E-stained lung tissues. B, small bronchioles; V, vasculature. Insets show larger views of inflammation sites. Scale bars: $25 \mu \mathrm{m} ; 200 \mu \mathrm{m}$ (insets). Each photomicrograph is representative of 4 mice.

\section{Results}

pAgs evoke significantly heightened pulmonary pathological responses compared with sAgs in sensitized mice. Initially, we compared the ability of extracts from 2 natural allergens, house dust mite (HDM) and Short Ragweed pollen (RW), to determine whether a corresponding difference exists between the 2 forms of allergen in their ability to recruit eosinophils, a key inflammatory cell type implicated in allergic asthma (11), we obtained BAL and lung tissue from sensitized mice 48 hours after challenge with allergens. As shown in Figure 1, B and C, although both sAgs and pAgs provoked significant eosinophil influx into the BAL and lung tissue compared with the saline control, pAgs induced significantly more eosinophil infiltration than did sAgs. Consistent with this observation, histological examination of pAg-challenged lung tissue revealed greater eosinophil accumulation around bronchioles and the vasculature than in sAg-challenged lung tissue (Figure 1D). Notably, there was minimal pulmonary eosinophilia observed in sensitized mice challenged with unconjugated blank particles (no allergens; Figure 1, A-D), which indicates that the observed effects were antigen dependent and not merely due to the presence of particles. Taken together, our data demonstrate that with regard to eosinophil infiltration, the 2 primary hallmarks of allergic asthma, allergens in pAg form evoked significantly greater pathological responses than did allergens in $\mathrm{sAg}$ form in sensitized mice.

MCs mediate the enhanced pathological responses evoked by pAgs. The differential pathological responses evoked by sAgs and pAgs in the respiratory tract could be attributable to divergent responses 

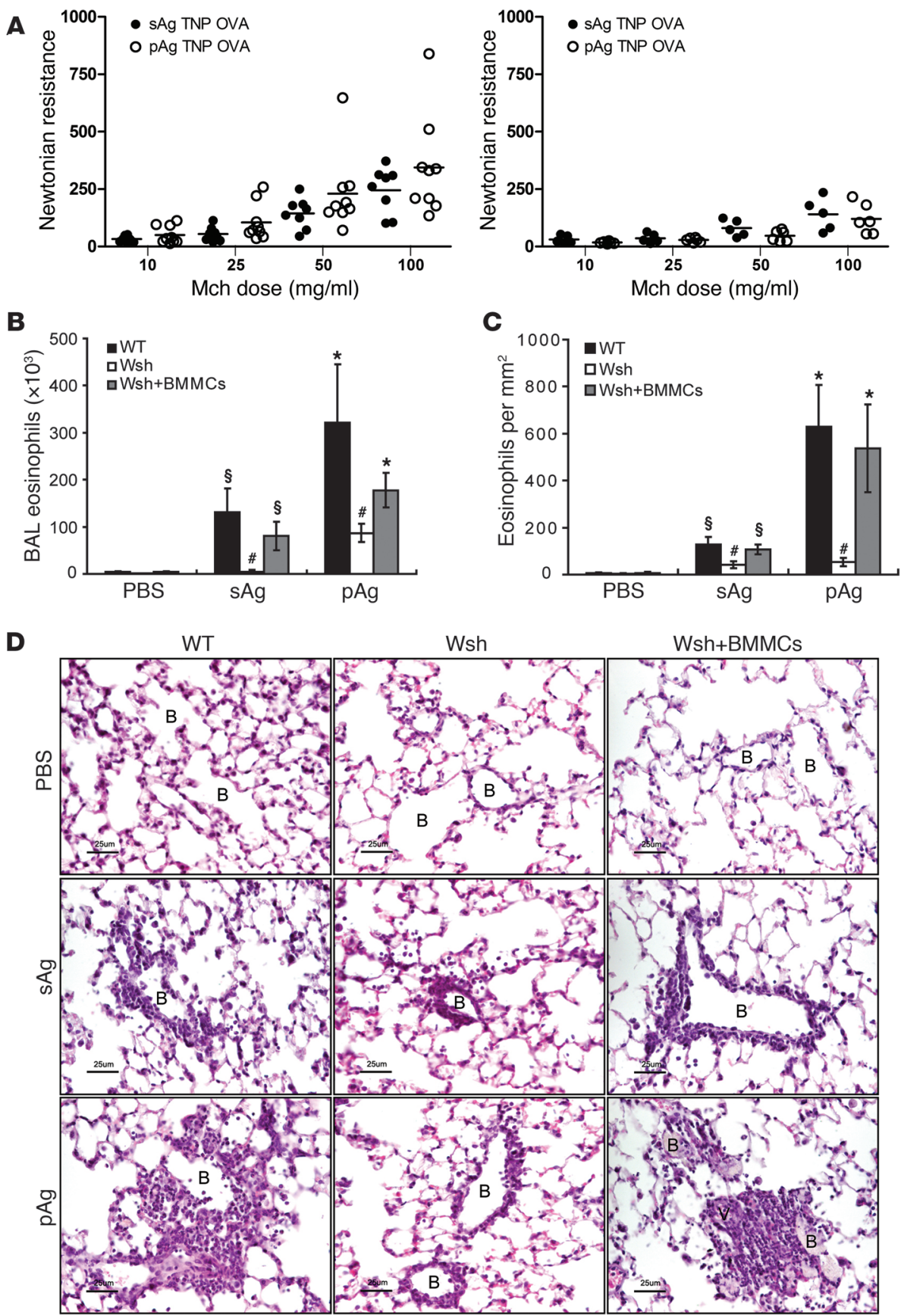

Figure 2

MCs are required for pulmonary pathological responses to pAgs and sAgs in sensitized mice. Pulmonary pathological responses in OVA/TNPsensitized mice after exposure to soluble OVA/TNP (sAg) or particles conjugated with OVA/TNP (pAg). (A) AHR at 24 hours after challenge in WT (left) or mast cell-deficient (Wsh) mice (right). (B) BAL eosinophil counts and (C) lung histology in WT, Wsh, and BMMC-repleted Wsh mice were examined at 48 hours after the challenge. In panels $\mathbf{B}$ and $\mathbf{C}$, for WT mice, $n=4,{ }^{\star} P<0.05$, pAg vs. sAg; $\$ P<0.01$, sAg vs. PBS; for BMMC-repleted Wsh mice: $n=4,{ }^{\star \star} P<0.05$, pAg vs sAg; $\$ \S P<0.01$, sAg vs. PBS. Eosinophil responses to sAg or pAg in Wsh mice were largely attenuated than in WT mice or BMMCs repleted Wsh mice $\left(n=4,{ }^{\#} P<0.05\right)$. (D) H\&E-stained lung tissue images in WT, Wsh, and BMMC-reconstituted Wsh mice show eosinophils accumulating around small bronchioles $(\mathrm{B})$ and vasculature (V). Data are representative of samples from 4 mice. Scale bars: $25 \mu \mathrm{m}$.

evoked by one or more immune surveillance cells (12). MCs are strategically located underneath the airway epithelium and are widely known for their contribution to the pathology induced by allergens in IgE-sensitized hosts $(13,14)$. To investigate the possible contri- bution of MCs, we first examined tissue sections of pAg-challenged lungs from sensitized mice to see if pAgs coupled to HDM or RW allergens could penetrate the epithelial barrier and directly interact with these immune surveillance cells. Samples taken 6 hours 

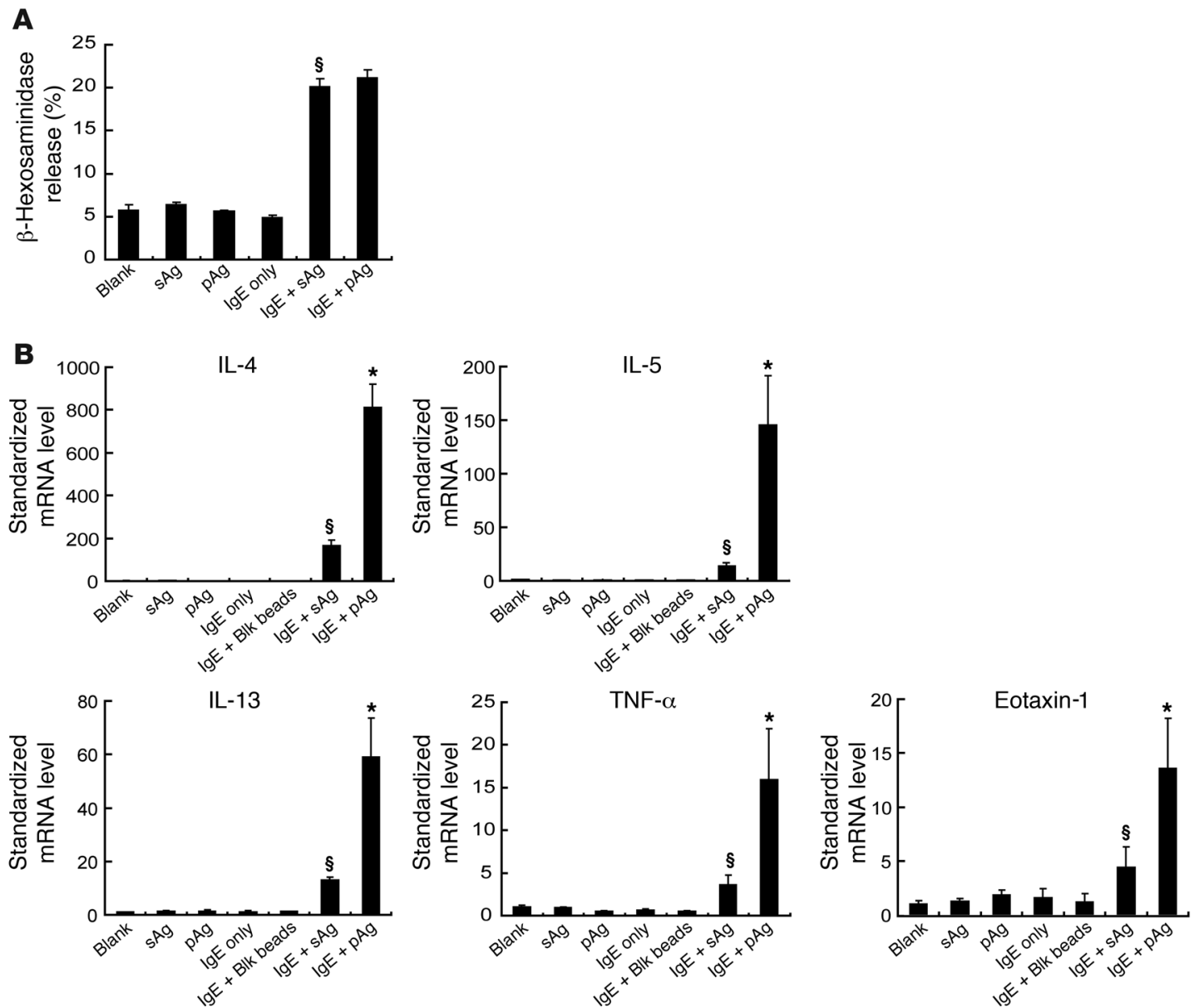

C
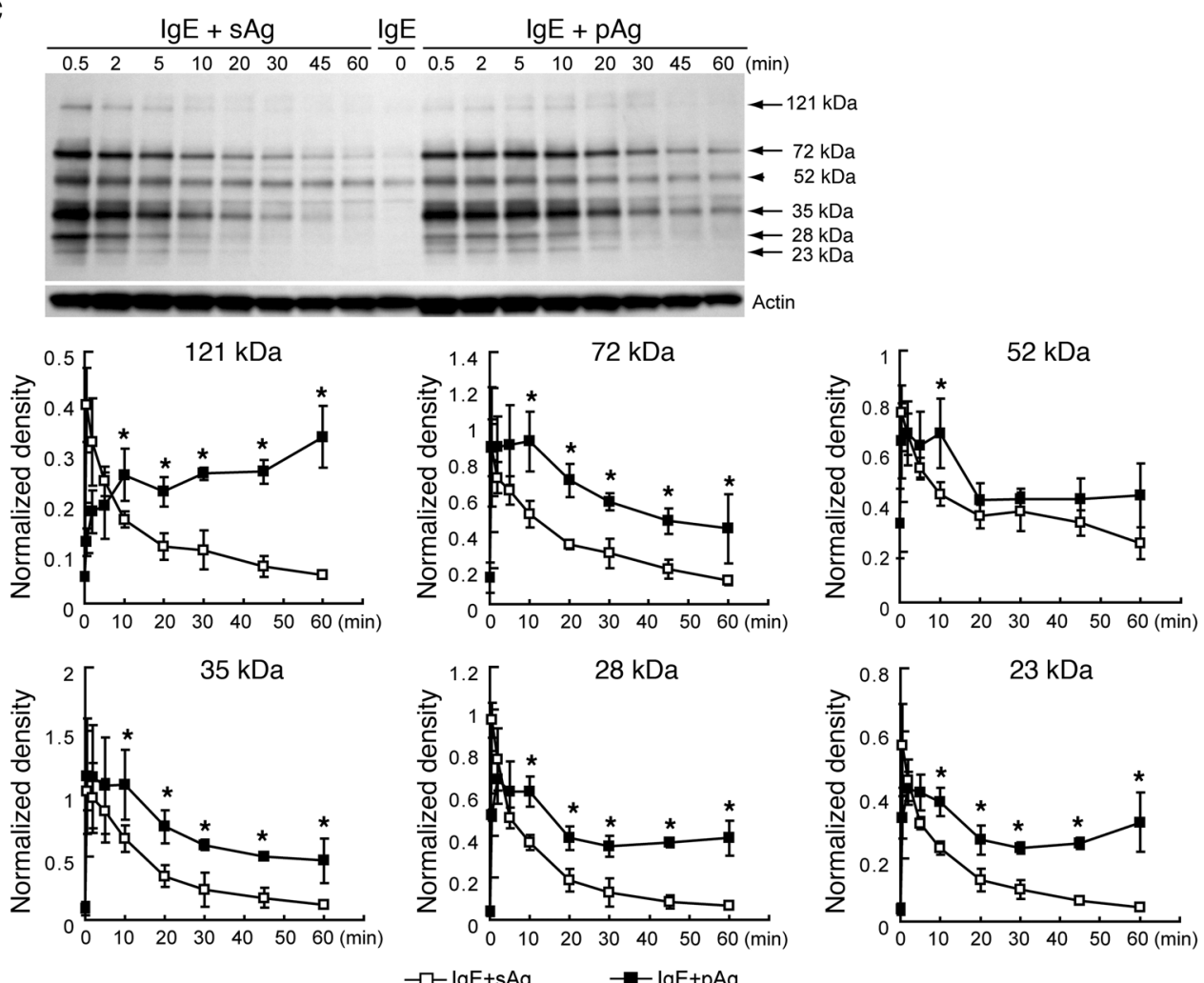


\section{Figure 3}

Differential cytokine and chemokine responses of BMMCs after exposure to sAgs or pAgs. TNP-specific IgE-sensitized BMMCs were challenged with $1 \mu \mathrm{g} \mathrm{sAg}$ (OVA/TNP) or pAg (particles coated with OVA/TNP). (A) At 1 hour after allergen exposure, MC degranulation was assessed by $\beta$-hexosaminidase release $(n=3) . ~ \$ P<0.01$ versus vehicle. (B) De novo synthesis of proinflammatory mediators. At 1 hour after exposure, mRNA expression levels of IL-4, IL-5, IL-13, TNF- $\alpha$, and eotaxin- 1 in BMMCs were determined by real-time PCR $(n=4)$. Untreated BMMCs, unsensitized BMMCs challenged by sAgs or pAgs, and sensitized BMMCs without challenge or exposed to blank beads served as controls. $\$ P<0.01$ versus controls; ${ }^{\star} P<0.01$ versus sAg. (C) Anti-phosphotyrosine Western blot of proteins from IgE-sensitized BMMCs following exposure to sAgs or pAgs. In all cases (arrows) except a 52-kDa band (arrowhead), phosphorylation evoked by pAgs appeared appreciably more sustained than that by sAgs. Blot is representative of 4 separate experiments. The intensity of phosphorylation of prominent proteins at various time points was also assessed using densitometry, using actin as the internal quantitative control. ${ }^{*} P<0.01$ versus sAg.

(Supplemental Figure 4A; supplemental material available online with this article; https://doi.org/10.1172/JCI43584DS1) and 24 hours (data not shown) after challenge revealed pAgs in direct contact with MCs located beneath the epithelium, which suggests that after lung challenge, pAgs can penetrate the epithelium and directly interact with MCs for prolonged periods of time. Next, to evaluate the possible contribution of MCs to the differential allergic responses evoked by sAgs and pAgs, we compared eosinophil influx in WT and MC-deficient Kit $t^{W-s h} / K i t^{W-s h}$ (Wsh) mice using the widely used model allergen OVA conjugated to the small hapten molecule trinitrophenol (TNP; ref. 14). The benefit of this allergen relative to natural allergens is that it has no intrinsic protease activity that might complicate the identification of distinct pathways specifically activated by the physical nature of pAgs. Thus, any perceived heightened pathological responses to pAgs compared with sAgs can be readily attributable to the particulate nature of the allergen. We also verified that OVA/TNP-conjugated particles can penetrate the airway epithelium and interact with MCs found underneath the epithelium (Supplemental Figure 4B). As seen with natural allergens, eosinophilia evoked by OVA/TNP in pAg form was markedly more enhanced than in sAg form in WT sensitized mice (Figure 2, A-D). Notably, challenge of sensitized mice with OVA/TNP sAg mixed with unconjugated particles induced responses comparable to those with sAgs alone (Supplemental Figure 5), which confirmed that the blank particles did not have any inherent capacity to evoke inflammatory responses. Furthermore, examination of BAL and lung tissue revealed that eosinophil influx was substantially reduced in sensitized Wsh mice challenged by pAgs compared with that in WT mice (Figure 2, B-D). These data suggest that MCs modulate the recruitment of eosinophils into the lung. However, pAgs recruited a modest amount of eosinophils into the lungs of Wsh mice (Figure 2, B-D), which suggests that other cells may also be involved. Reconstitution of Wsh mice with WT bone marrow-derived MCs (BMMCs) completely restored sAg- and pAg-induced eosinophilia to levels comparable to those in WT mice (Figure 2, A-D), which suggests that MCs are required for both OVA/TNP sAg- and OVA/TNP pAg-induced increases in the induction of eosinophilia. Similar to OVA/TNP pAg, HDM pAg and RW pAg failed to induce eosinophilia in sensitized Wsh mice (data not shown), which suggests that the observed defects in Wsh mice are not unique to OVA/TNP. Therefore, MCs are required for sAgs and pAgs to induce eosinophilia in sensitized mice.

Finally, our sensitization procedure is known to provoke antigen-specific IgE and IgG1 both, which might contribute to MC activation in our model $(15,16)$. Consistent with this notion, challenge of nonsensitized mice with OVA/TNP sAg or OVA/TNP pAg failed to elicit eosinophilia (Supplemental Figure 6). To parse the dependence of our model on either antibody isotype, we passively transferred anti-TNP IgE or anti-TNP IgG1 into WT mice, followed by challenge with OVA/TNP in sAg or pAg form. As demonstrated in Supplemental Figure 7, challenge of mice with passively transferred IgE resulted in elevated eosinophil responses compared with saline controls. Notably, challenge of these mice with pAgs resulted in markedly elevated responses compared with sAg-challenged mice. In contrast, neither sAgs nor pAgs were able to induce a response in mice infused with OVA/TNP-specific IgG1 (Supplemental Figure 7), which suggests that the observed responses in our model are dependent upon anti-TNP IgE. Collectively, these data suggest that MC engagement of IgE/sAg or pAg complexes are required for elevated eosinophilia in the murine lung. Moreover, these data suggest that the differential responses generated by either IgE/sAg or pAg complexes requires direct interaction with MCs.

pAgs trigger a beightened cytokine and chemokine response from MCs compared with sAgs. The results of our in vivo studies strongly suggested that IgE-sensitized MCs mediate more potent inflammatory responses to pAgs than to sAgs in the lung. To better understand this observation, we turned to an in vitro model to study the effects of sAg- and pAg-induced IgE crosslinking on the surface of cultured BMMCs. To do this, IgE-sensitized BMMCs were challenged with equal amounts of OVA/TNP sAg or OVA/TNP pAg and examined their ability to undergo degranulation and mediate cytokine/ chemokine expression in vitro. As shown in Figure 3A, exposure of TNP-specific IgE-sensitized BMMCs to sAgs or pAgs resulted in the release of similar amounts of $\beta$-hexosaminidase, which suggests that degranulation responses of BMMCs to both challenges were identical. Remarkably, examination of IL-4, IL-5, IL-13, TNF- $\alpha$, and eotaxin-1 responses of TNP-specific IgE-sensitized BMMCs to sAgs or pAgs by quantitative RT-PCR revealed that pAgs triggered 4- to 5-fold higher production of each cytokine or chemokine mRNA compared with sAg responses (Figure 3B). The mediators we examined have previously been implicated in triggering allergic asthma symptoms (17-19). Using IL-4 as the representative mediator, we further examined MC cytokine responses evoked by sAgs and pAgs at 1, 6, and 12 hours and observed that the differential responses were evident even at 12 hours after challenge, albeit to a much lower extent than those of the 1-hour response, which were maximal (Supplemental Figure 8A). It is also noteworthy that the heightened de novo synthesis of cytokine and chemokine mRNAs evoked by the pAg relative to its sAg counterpart occurred despite variations in the protein amount on beads, the ratio of beads to cells, and the size of beads (Supplemental Figure 8, B-D). Furthermore, when we examined BMMC culture supernatants for IL-4 secretion after exposure to sAgs and pAgs, we found that it paralleled our findings with de novo synthesis of IL4 mRNA (Supplemental Figure 8E). Taken together, these observations suggest that MCs can discriminate between pAgs and sAgs and that it evokes a markedly more enhanced response to the former.

To elucidate the molecular basis for the enhanced MC de novo synthesis evoked by pAgs relative to sAgs, we compared FceRI-mediated tyrosine phosphorylation signaling in TNP-specific IgE- 
$5 \min$
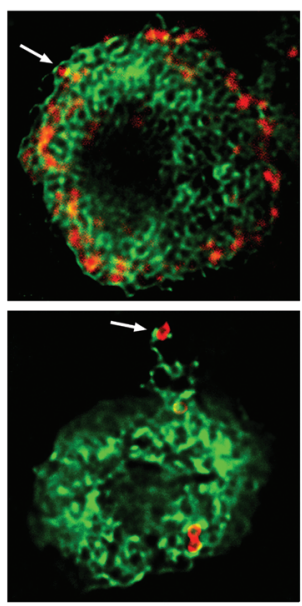

5 min

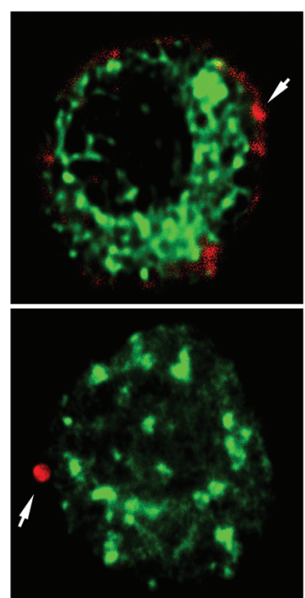

$5 \mathrm{~min}$
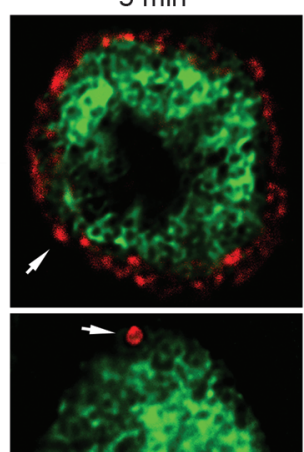

$\lg E$
$30 \mathrm{~min}$
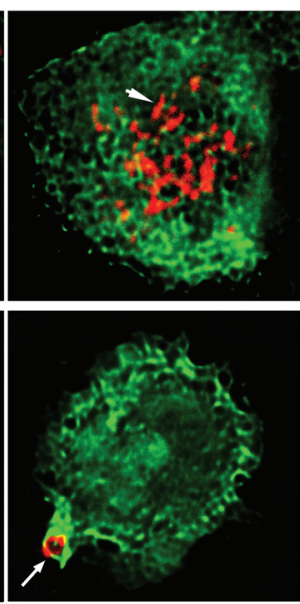

$30 \mathrm{~min}$

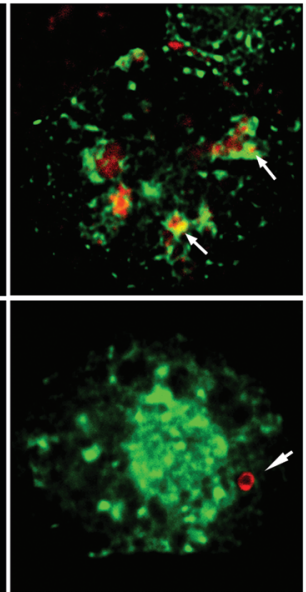

$30 \mathrm{~min}$
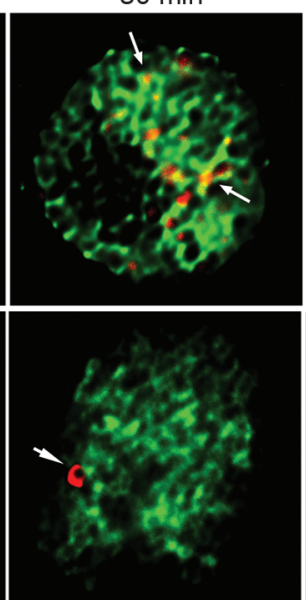

$60 \mathrm{~min}$
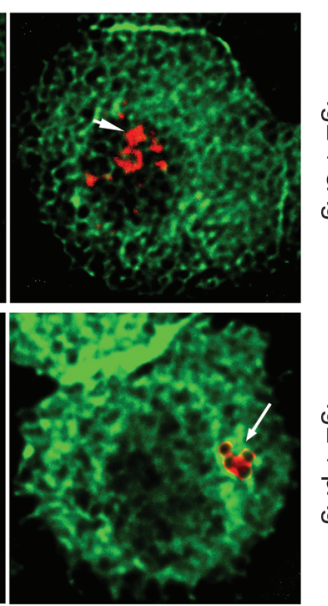

$60 \mathrm{~min}$

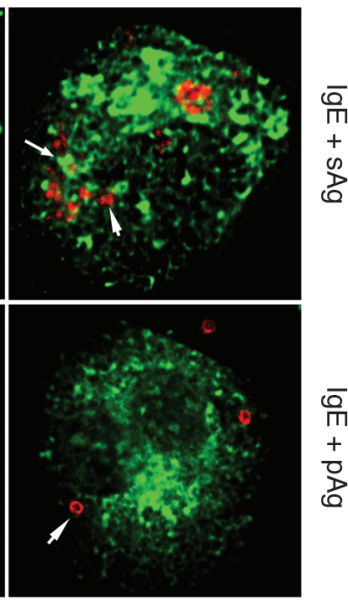

$60 \mathrm{~min}$

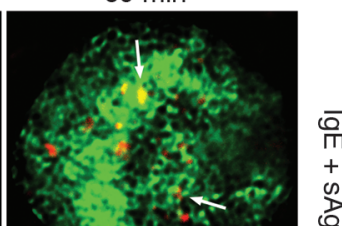

1
+
0
0

후

$+$

ह

$\ddot{\Pi}$

$\stackrel{+}{\stackrel{7}{8}}$

$\overline{0}$
+1
0
0

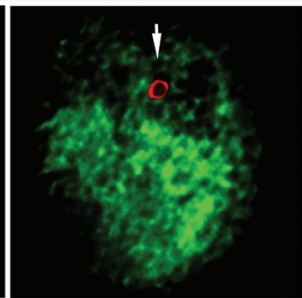

\section{Figure 4}

Internalized sAgs and pAgs follow different endocytic pathways in BMMCs. Endocytosis of sAgs or pAgs was investigated in BMMCs stably transfected with GFP.

CD63, GFP-Rab5, or GFP-Rab7.

Confocal microscopic images of each transfected BMMC type prior to addition of allergen are shown. Images of GFP-transfected MCs containing allergen prelabeled with Alexa Fluor 546 (red) were collected at 5,30 , and 60 minutes. Arrows denote examples of allergens encased in GFP-positive compartments. Arrowheads denote examples in which no colocalization is evident. All pictures are representative of 3 separate experiments. Scale bars: 5 um. sensitized BMMCs challenged with either sAgs or pAgs. As shown in Figure 3C, both allergens elicited comparable phosphorylation patterns. However, the most obvious difference observed between sAg- and pAg-mediated signaling was that the phosphorylation levels of most prominent proteins were significantly more sustained after pAgs challenge than after sAg challenge (Figure 3C). In good agreement with this observation, evaluation of 3 separate tyrosine residues on the critical $\operatorname{IgE}$ signaling intermediate
Syk demonstrated that pAgs elicited prolonged phosphorylation patterns compared with those elicited by sAgs (Supplemental Figure 9). Conceivably, the heightened and sustained cytokine and chemokine production elicited by pAgs from BMMCs is related to prolonged FceRI signaling rather than to any specific difference in the signaling circuitry.

pAgs are internalized via an endocytic pathway in MCs distinct from that of sAgs. Although our data showed that pAgs evoke markedly great- 
er IL-4, IL-5, IL-13, TNF- $\alpha$, and eotaxin- 1 responses from MCs than sAgs, the early MC signaling events as well as the degranulation response to pAgs and sAgs were comparable. Indeed, the major difference thus far identified was that FceRI signaling events initiated by pAgs were more sustained than those initiated by sAgs. Therefore, we reasoned that the enhanced cytokine and chemokine response to pAgs is attributable to differences in the rapidity of FceRI signal termination. Endocytosis is a principal mechanism for receptor downregulation and termination of signal transduction including FceRI $(20,21)$. Therefore, we initially characterized the endocytic routes the IgE/FceRI/antigen complexes took after challenge of TNP-specific IgE-sensitized BMMCs with pAgs or sAgs. To do this, we created BMMCs expressing specific GFP fusion proteins that specifically identify the vesicular membranes of secretory granule compartments (CD63), early endosomes (Rab5), or late endosomes/lysosomes (Rab7; refs. 22-24). GFP-transfected BMMCs were passively sensitized and exposed to fluorescent sAgs or pAgs. Confocal microscopic analysis revealed that sAgs and pAgs followed markedly different endocytic trafficking pathways. Within 5 minutes of engaging IgE/FceRI, sAgs localized in $\mathrm{CD}^{+} 3^{+}$compartments (Figure 4). Note that since CD63 is a secretory granule membrane component, internalized sAgs were visualized encased within $\mathrm{CD} 63^{+}$compartments. Thereafter, the sAgs moved from the peripheral areas toward the center of the cell. In so doing, sAgs transited from $\mathrm{CD}^{+} 3^{+}$compartments into Rab5 ${ }^{+}$ and $\mathrm{Rab} 7^{+}$vesicles. Indeed, by 1 hour, most sAgs were located in either Rab5 ${ }^{+}$or Rab7 ${ }^{+}$vesicles. In contrast, pAgs remained encased in $\mathrm{CD} 3^{+}$compartments. These compartments did not become positive for Rab5 or Rab7 markers for the duration of the experiment (Figure 4). These data suggest that whereas sAg/IgE/FceRI complexes follow a traditional endocytic trafficking pathway ending in the lysosome, $\mathrm{pAg} / \mathrm{IgE} / \mathrm{Fc \varepsilon RI}$ complexes are retained in $\mathrm{CD} 3^{+}$secretory compartments and fail to traffic further. This unique location of $\mathrm{pAg} / \mathrm{IgE} / \mathrm{Fc \varepsilon R} \mathrm{R}$ complexes in nondegradative compartments may result in sustained FceRI signaling and elevated de novo synthesis of cytokine and chemokines by MCs.

$p A g / I g E / F c \varepsilon R I$ complexes are retained in lipid raft-enriched compartments. Our previous study revealed that the FceRI-mediated phagocytosis of pollen into MCs is lipid raft dependent (25). Lipid rafts are specialized membrane domains that are dynamic assemblies of proteins, lipids and signaling substrates (26-28). Recent studies showed that lipid rafts promote many critical signaling activities of MCs, including recruitment of signaling molecules that mediate FceRI signaling (29-32) as well as endocytosis of IgE/FceRI complexes $(25,33,34)$. To investigate the spatial localization of lipid raft microdomains and compartments housing allergens, we examined resting BMMCs for lipid rafts. Many of the lipid raft-enriched microdomains, stained by fluorescent cholera toxin subunit B, a probe for lipid rafts (27), appeared encased in membranes that stained for CD63 (Supplemental Figure 10). To explain the sustained signaling associated with $\mathrm{pAg}$-mediated MC activation, we hypothesized that the internalization of $\mathrm{pAg} / \mathrm{IgE} / \mathrm{FccRI}$ complexes into nondegradative, lipid raft-enriched $\mathrm{CD} 3^{+}$compartments allows the $\mathrm{pAg} / \mathrm{IgE} / \mathrm{FccR} I$ complex to avoid degradation and maintain sustained signaling. To investigate whether the sustained signaling evoked by pAgs is related to retention of internalized pAg/ $\mathrm{IgE} / \mathrm{Fc \varepsilon RI}$ complexes within lipid raft-enriched compartments, we compared pAg- and sAg-induced duration of IgE/FceRI complex association with lipid rafts. We used fluorescently labeled IgE to sensitize BMMCs before exposure to pAgs or sAgs, and at var- ious time points after challenge, BMMCs were fixed and stained by fluorescent cholera toxin subunit B (27). For both sAgs and pAgs, as early as 30 seconds after exposure to allergen, IgE/FceRI complexes entered and associated with lipid raft domains (Figure 5A). However, 10 minutes thereafter, sAg-crosslinked IgE/FceRI complexes rapidly separated from lipid raft area and transitioned into compartments that were not enriched in lipid rafts. In contrast, pAg-crosslinked IgE/FceRI complexes remained in lipid raftenriched compartments for the duration of the experiment (Figure $5 \mathrm{~A})$. Our microscopy data suggest that the time course of lipid raft colocalization varies greatly, depending on whether the allergen is delivered in soluble or particulate form.

To confirm the dynamics for the association of IgE/FceRI complexes with lipid raft domains in MCs, we isolated lipid raft fractions from sensitized BMMCs at various time points after exposure to sAgs or pAgs. Each lipid raft fraction was then probed for the presence of the FceRI- $\gamma$ chain on Western blots. Although some of the FceRI- $\gamma$ chain was found associated with lipid raft fractions at baseline (defined by the localization of flotillin, an integral component of lipid rafts; ref. 26), substantial recruitment of FceRI- $\gamma$ was observed immediately after exposure to either allergen. However, 5 minutes after exposure, the amount of FceRI- $\gamma$ chain in the sAg-induced lipid raft fractions was greatly reduced (Figure 5B), suggestive of their movement out of the lipid raft-enriched domains into a non-lipid raft compartment. By 10 minutes, almost all FceRI- $\gamma$ had left the lipid raft fractions. In contrast, the high amounts of recruited FcERI- $\gamma$ chain triggered by pAgs remained in the lipid raft fractions for at least 1 hour (Figure 5B). To determine whether the prolonged presence of FceRI- $\gamma$ in the lipid rafts was accompanied by sustained signal transduction, we probed the lipid raft fractions (fractions 4 and 5) derived from pAg-or sAg-challenged BMMCs for tyrosine-phosphorylated proteins as a general marker of FceRI signaling. Compared with sAg lipid fractions, pAg lipid fractions contained markedly greater amounts of phosphorylated proteins for a longer period of time (Figure 5C). Collectively, these data suggest that after engagement of IgE/FceRI complexes by sAgs, the signaling complex moves within seconds into lipid raft compartments where signaling is initiated. The sequential transition out of lipid rafts and into classical endocytic compartments of sAg/IgE/FceRI complexes is accompanied by the termination of signaling responses. In the case of pAgs, the $\mathrm{pAg} / \mathrm{IgE} / \mathrm{FccR} \mathrm{R}$ signaling complexes move into lipid raft-enriched compartments, where they remain for prolonged periods of time, accompanied by a sustained signaling response.

Inbibition of IgE-mediated endocytosis of sAgs results in enhanced MC mediator responses comparable to those evoked by pAgs. Based on the evidence that the endocytic route used by pAgs was distinct from that followed by sAgs and that retention of pAgs in lipid raft-enriched compartments resulted in augmented MC responses, we hypothesized that it would be possible to enhance the signaling capabilities of sAgs to levels seen with pAgs merely by prolonging the association of $\mathrm{sAg} / \mathrm{IgE} / \mathrm{Fc \varepsilon RI}$ complexes within lipid raft-enriched compartments. We evaluated 2 methods of prolonging this association: use of the pharmacological agent latrunculin $\mathrm{B}$ and selective knockout of caveolin-1, a protein involved in lipid raft-mediated endocytosis. Latrunculin B is an actin depolymerizing agent that disrupts endocytic activities of FceRI but does not influence crosslinking of FceRI by allergens (35-38). By pretreating sensitized BMMCs with latrunculin B, we expected to retard the endocytosis of sAg/IgE/FceRI complexes and the accompanying disassociation of these complexes from lipid raft fractions. IgE-sensitized 
A

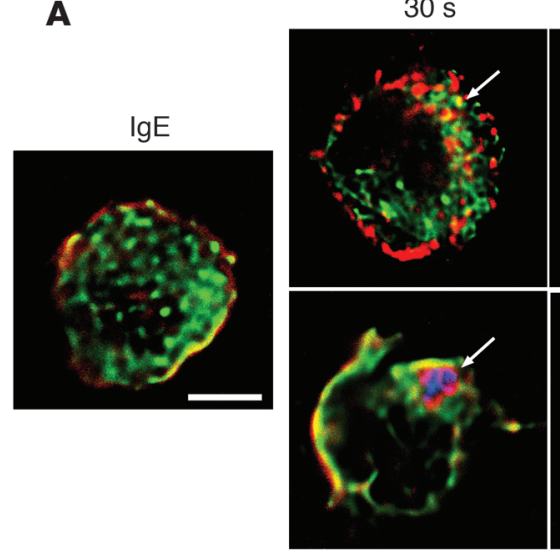

$5 \min$

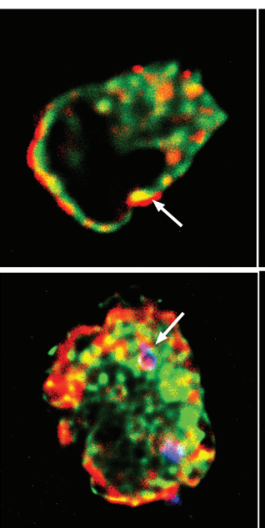

$10 \min$
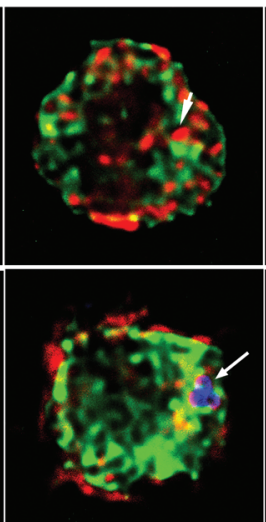

$30 \mathrm{~min}$
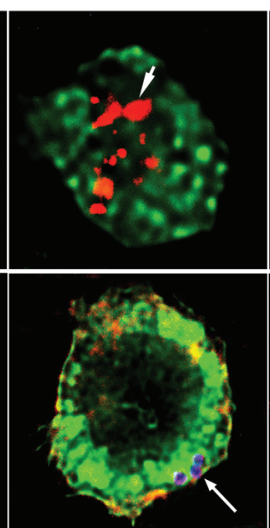

$60 \mathrm{~min}$

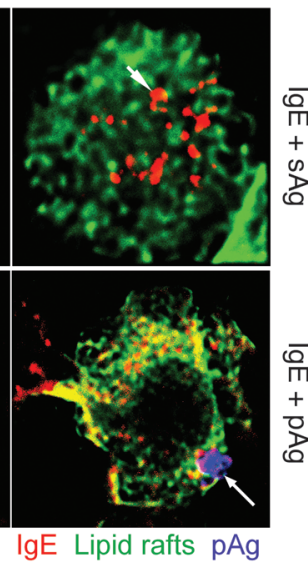

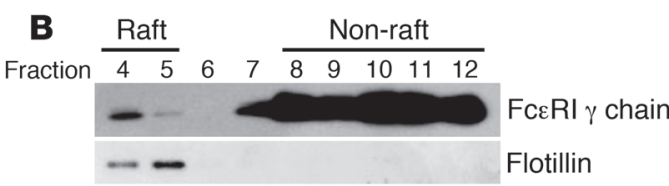

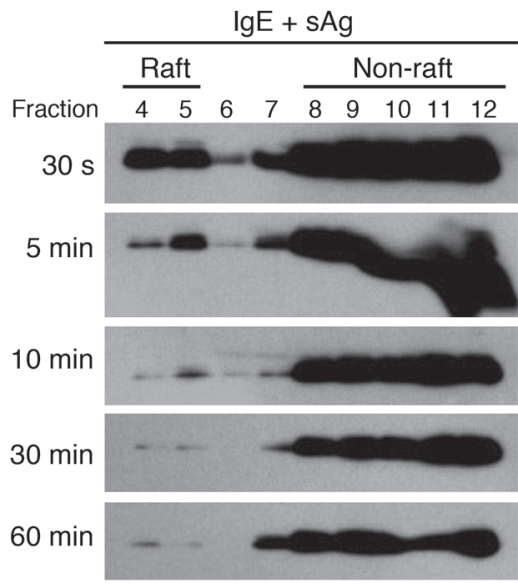

Flotillin

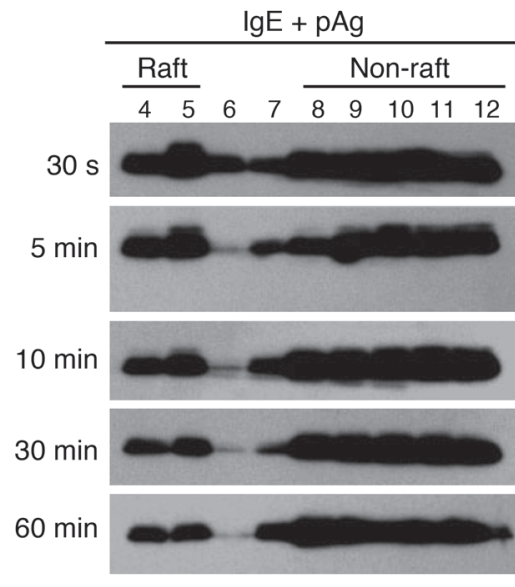

C

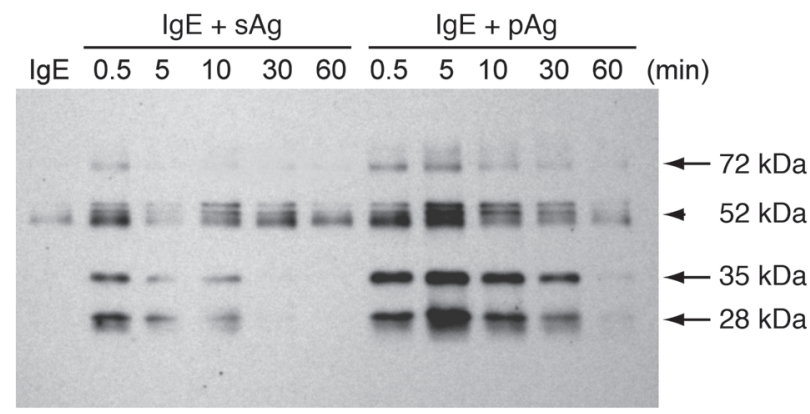

\section{Figure 5}

$\operatorname{lgE} / F c \varepsilon R I$ complexes are retained within lipid raftenriched domains of BMMCs following exposure to pAgs, but not to sAgs. (A) Association of lgE/ FceRI complexes (red) with lipid rafts (green) at the indicated time points following exposure to sAgs or pAgs. Shown in blue are pAgs. Arrows denote examples of colocalization between lgE/ FceRI complexes and lipid raft-enriched regions. Arrowheads denote examples in which IgE/FceRI complexes have separated from lipid raft-enriched compartments and no colocalization is evident. Scale bar: $5 \mu \mathrm{m}$. (B) Association of FceRl- $\gamma$ chain with lipid raft fractions in sensitized BMMCs before and at various time points after exposure to sAgs or pAgs. Cell fractions were obtained after sucrose gradient centrifugation and probed for FceRl- $\gamma$ chain on a Western blot. Distribution of FcERI- $\gamma$ chain in cell fractions prior to addition of allergen is also shown. Based on the location of flotillin-1, fractions 4 and 5 are defined as the lipid raft fractions. (C) Sucrose gradient fractions 4 and 5 were pooled and subjected to Western blot to detect tyrosine phosphorylation within lipid fractions of BMMCs at various time points after exposure to sAgs or pAgs. Arrows denote phosphorylated bands that appeared more intense in pAg- relative to sAg-stimulated cells. Arrowhead denotes a band for which differences between sAg- and pAg-stimulated cells was not marked. Images are representative of 3 separate experiments.
BMMCs were pretreated with $4 \mu \mathrm{M}$ latrunculin $\mathrm{B}$ for 15 minutes before challenge with sAgs. Latrunculin B treatment enhanced colocalization of sAg/IgE/FceRI complexes within lipid raft components for up to 1 hour (Figure 6A). A prolonged association of $\mathrm{sAg} / \mathrm{IgE} / \mathrm{FccRI}$ complexes within $\mathrm{CD} 3^{+}$compartments lasting at least 1 hour was also observed with treatment of the actin depolymerizing agent (Figure 6B). Latrunculin B treatment also prolonged and enhanced sAg-induced localization of the Fce RI- $\gamma$ chain and phosphorylated proteins in the lipid raft fractions of
BMMCs, to levels nearly comparable to those induced by pAgs (Figure 6C). As predicted, latrunculin B treatment enhanced the expression of IL-4 in IgE-sensitized BMMCs exposed to sAgs, to the same levels induced by pAgs (Figure 6D).

Next, we examined the effect of knocking out a cellular component involved in the uptake of allergens in MCs. Caveolin-1 is a $22-\mathrm{kDa}$ membrane protein integral to lipid rafts that has been implicated in lipid raft-mediated endocytic trafficking $(36,39-$ 41). We hypothesized that endocytosis of sAgs and subsequent 
A $\lg \mathrm{E}$

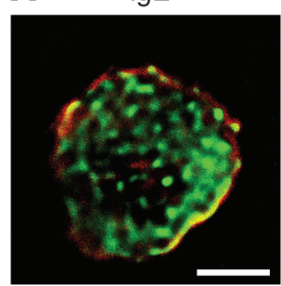

$30 s$
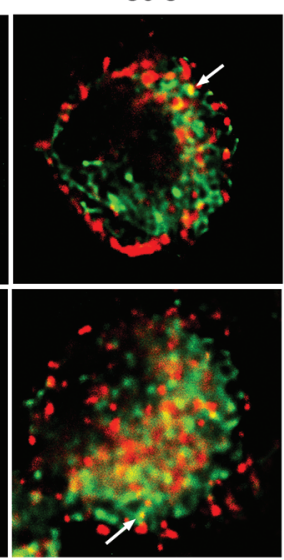

$5 \min$
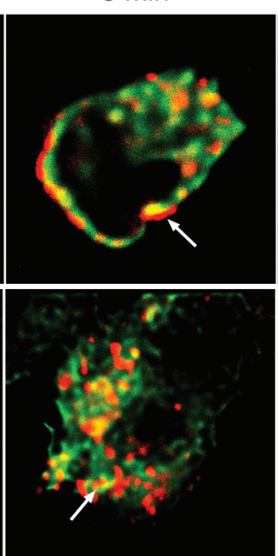

$10 \min$
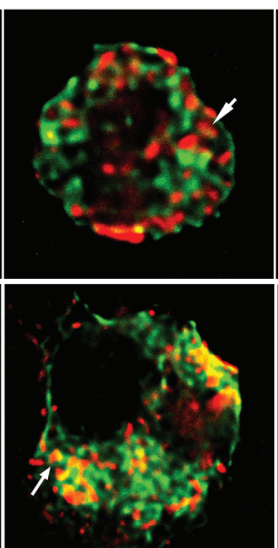

$30 \mathrm{~min}$
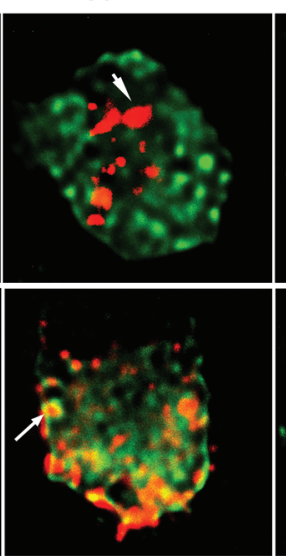

$60 \min$
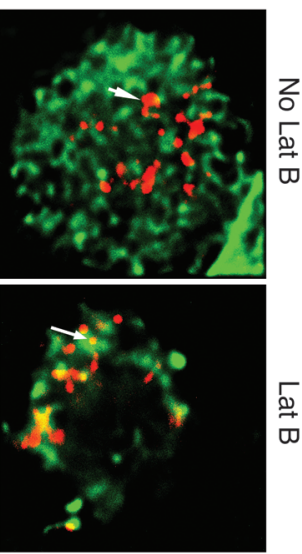

IgE Lipid rafts
B

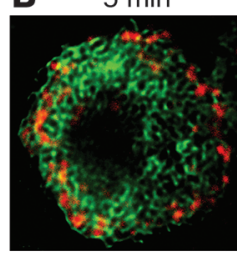

$30 \mathrm{~min}$
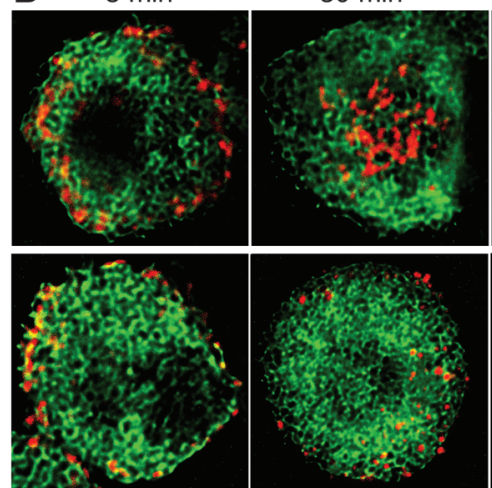

60 min
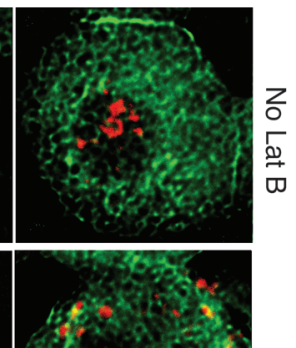

$\underset{\substack{0 \\ \infty}}{\infty}$
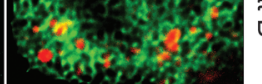

OVA/TNP CD63

C No Lat B Lat B No Lat B

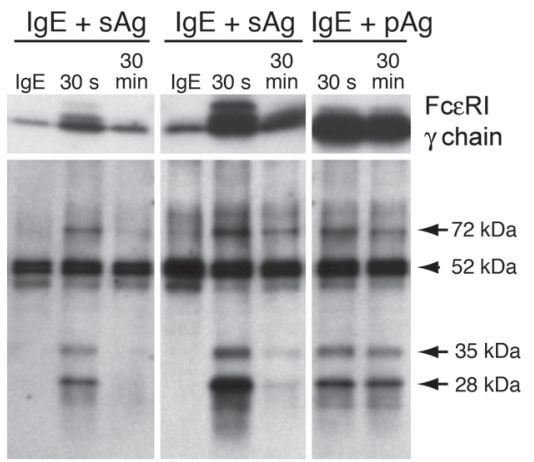

IL-4

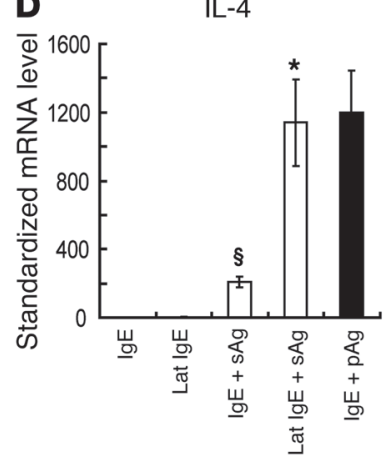

Figure 6

The endocytic and signaling responses of BMMCs to sAgs following pretreatment with latrunculin $B$ (Lat $B$ ) is comparable to responses evoked by pAgs in untreated BMMCs. (A) Association of IgE/FceRI complexes (red) with lipid raft domains (green) in latrunculin B-treated and untreated BMMCs after exposure to sAgs. Arrows denote examples of colocalization of $\mathrm{IgE} / \mathrm{Fc \varepsilon RI}$ complexes with lipid rafts. Arrowheads denote areas where IgE/FcERI complexes have separated from lipid rafts. (B) Dynamic localization of sAgs (red) within GFP-CD63+ (green) compartments in latrunculin B-treated and untreated BMMCs. (A and B) Original magnification, $\times 100$. Scale bars: $5 \mu \mathrm{m}$. (C) Western blot to detect Fc\&RI- $\gamma$ chain and tyrosine-phosphorylated proteins in pooled lipid raft fractions. Arrows denote bands that were enhanced by sAgs following latrunculin B treatment. Arrowhead denotes a band that did not appear to change in strength after latrunculin B treatment. Data in AC are representative of 3 separate experiments. (D) Latrunculin B-treated BMMCs expressed higher levels of IL-4 than did untreated BMMCs 1 hour after sAg exposure $(n=4)$. ${ }^{*} P<0.01$ versus untreated BMMCs; $\$ P<0.01$ versus vehicle. The enhanced level of IL-4 expression was comparable to that induced by pAgs in untreated BMMCs (black bar).

trafficking out of lipid raft domains in caveolin-1-deficient $\left(\mathrm{Cav}^{-/-}\right)$BMMCs would be severely retarded, and as a result, the FceRI signaling and mediator responses seen in these cells would be enhanced and comparable to those normally observed in pAg-exposed sensitized WT $\left(\mathrm{Cav}^{+/+}\right)$BMMCs. Consistent with this hypothesis, exposure of sensitized $\mathrm{Cav}^{-/} \mathrm{BMMCs}$ to sAgs resulted in prolonged retention of the IgE/FceRI complex in lipid raft domains within the MC (Figure 7A). Interestingly, when we examined for the presence of the FceRI- $\gamma$ chain and tyrosine phosphorylation of signaling proteins in the lipid raft fractions in $\mathrm{Cav}^{-1}$ BMMCs following exposure to sAgs, we found that although the levels were not the same as seen with $\mathrm{Cav}^{+/+} \mathrm{BMMCs}$ treated with pAgs, the association was nevertheless stronger and more prolonged than that of sAg-exposed $\mathrm{Cav}^{+/+} \mathrm{BMMCs}$ (Figure 7B). In addition, exposure of IgE-sensitized $\mathrm{Cav}^{/-}$BMMCs to sAgs resulted in heightened expression of IL-4, to levels comparable to those observed in IgE-sensitized $\mathrm{Cav}^{+/+} \mathrm{BMMCs}$ following exposure to pAgs (Figure 7C). Notably, compared with the response of $\mathrm{Cav}^{+/+}$ BMMCs exposed to pAgs, the IL-4 responses of $\mathrm{Cav}^{-1-} \mathrm{BMMCs}$ to pAgs was also heightened (Figure 7C), and this parallels the prolonged association of key signaling components with lipid rafts in these Cav ${ }^{-1-}$ cells (Figure 7B).

Finally, to confirm that the sAg-induced signaling in $\mathrm{Cav}^{-/}$ BMMCs was functionally identical to that induced by pAgs in $\mathrm{Cav}^{+/+} \mathrm{BMMCs}$, we reconstituted MC-deficient Wsh mice with either $\mathrm{Cav}^{-/-}$or $\mathrm{Cav}^{+/+} \mathrm{BMMCs}$. The reconstituted mice were sensitized with OVA/TNP and airway challenged with either sAgs or pAgs as described above, and eosinophil influx were examined 48 hours after challenge. As demonstrated in Figure 7, D and E, challenge of $\mathrm{Cav}^{-/}$BMMC-reconstituted Wsh mice with sAgs resulted in robust eosinophil influx much higher than that seen in $\mathrm{Cav}^{+/+} \mathrm{BMMC}-$ reconstituted Wsh mice challenged with sAgs. 
A $\quad \lg E$
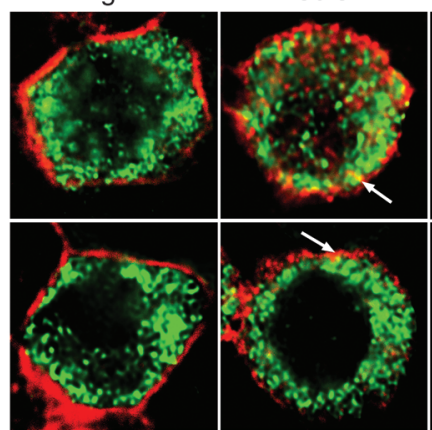

B

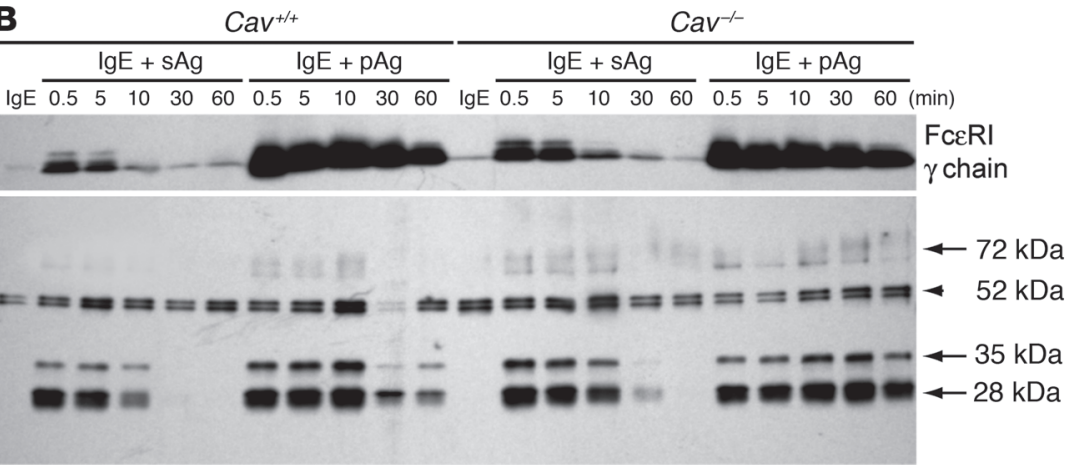

$30 s$
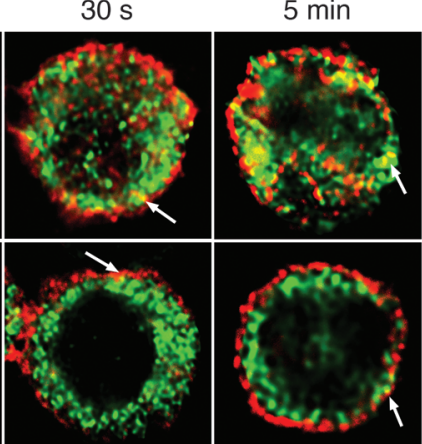

$10 \min$
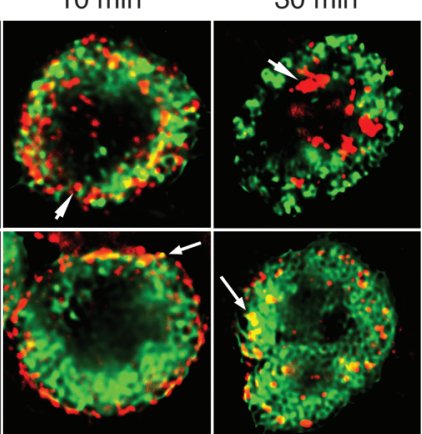

$60 \mathrm{~min}$
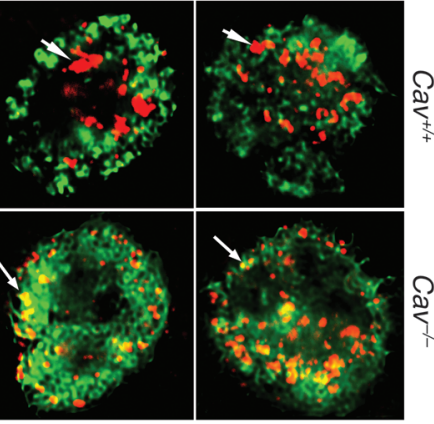

IgE Lipid rafts

C

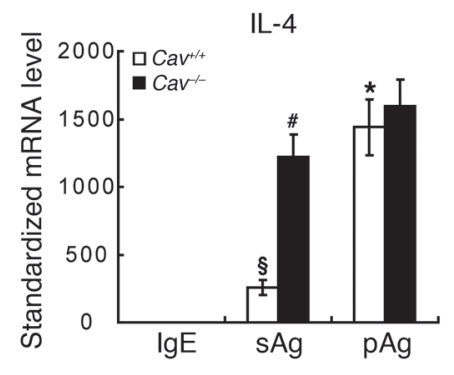

D

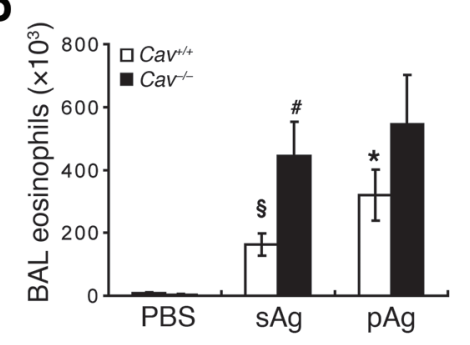

E

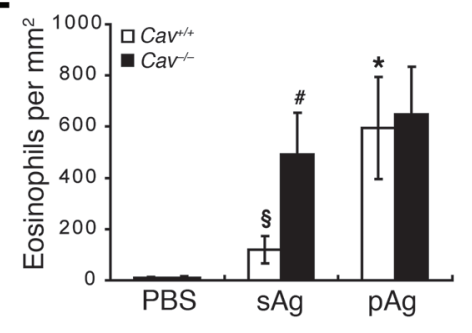

$\mathbf{F}$

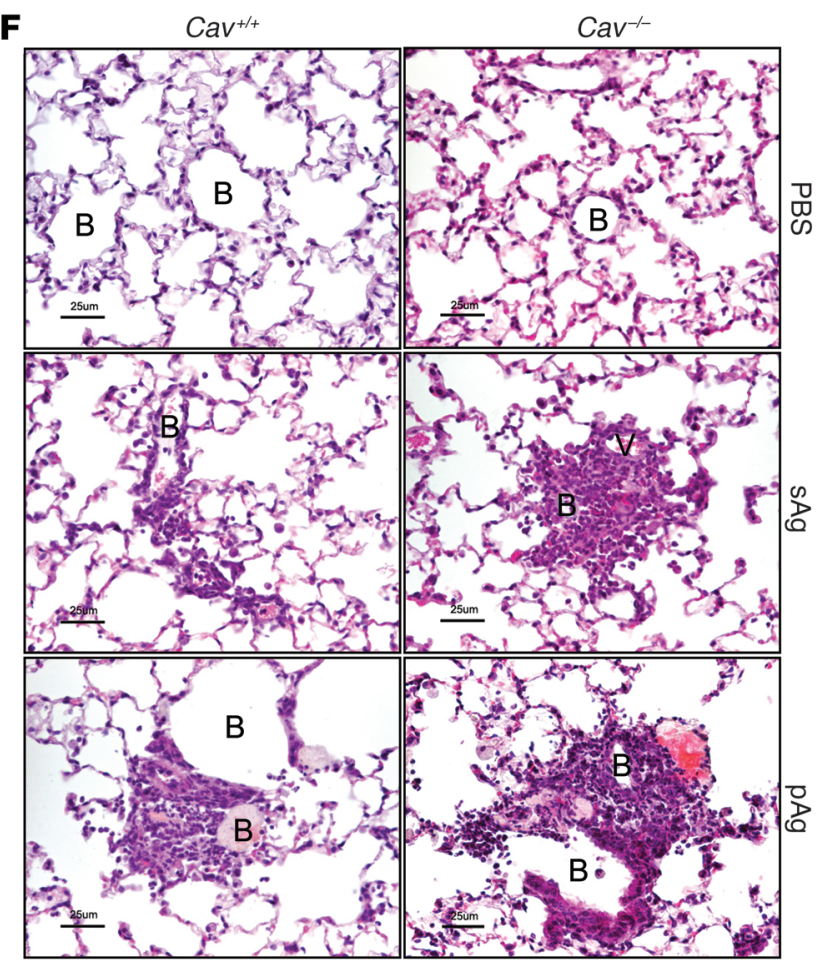




\section{Figure 7}

Caveolin 1 deficiency results in enhanced signaling responses of sAgs to levels similar to that induced by pAgs in WT BMMCs. (A) Association of IgE/FceRI complexes (red) with lipid rafts (green) in sensitized $\mathrm{Cav}^{+/+}$and $\mathrm{Cav}^{-/-}$BMMCs at different times after exposure to sAgs. Arrows denote examples of colocalization of IgE/FceRI complexes with lipid rafts. Arrowheads denote areas in which IgE/ FceRI complexes have separated from lipid rafts. Scale bars: $5 \mu \mathrm{m}$. Data are representative of 3 separate experiments. (B) FceRl- $\gamma$ chain and tyrosine-phosphorylated proteins in pooled lipid raft fractions from sensitized $\mathrm{Cav}^{+/+}$and $\mathrm{Cav}^{-/-}$BMMCs challenged with sAgs or pAgs. Arrows denote bands that were enhanced by sAgs in $\mathrm{Cav}^{-1-}$ BMMCs. Arrowhead denotes a band that did not appear to change in strength in $\mathrm{Cav}^{-1-}$ BMMCs. (C) Levels of IL-4 produced by sensitized $\mathrm{Cav}^{-/-}$and $\mathrm{Cav}^{+/+}$BMMCs 1 hour after sAg or pAg exposure $(n=4)$. BAL eosinophil counts (D), and lung histology (E) evoked by sAgs or pAgs in sensitized Wsh mice reconstituted with $\mathrm{Cav}^{-1-}$ BMMCs or $\mathrm{Cav}^{+/+}$BMMCs $(n=5)$. (C-E) $\$ P<0.01$ versus vehicle controls; ${ }^{*} P$ $<0.01$ versus $\mathrm{Cav}^{+/+} \mathrm{sAg}$; ${ }^{\#} P<0.01$ versus $\mathrm{Cav}^{+/+}$sAg. $(\mathbf{F})$ Histology of lungs from sensitized Wsh mice reconstituted with $\mathrm{Cav}^{-1-}$ BMMCs or $\mathrm{Cav}^{+/+} \mathrm{BMMCs}$ after exposure to sAgs or pAgs. Samples were stained with $\mathrm{H} \& \mathrm{E}$. Eosinophil accumulation around small bronchioles and vasculature is denoted. Each histological photomicrograph is representative of 4 mice. Scale bars: $25 \mu \mathrm{m}$.

The intensity of these enhanced responses were comparable to levels observed in pAg-challenged $\mathrm{Cav}^{+/+} \mathrm{BMMC}$-reconstituted Wsh mice. Histological examination showed a response pattern similar to that of BAL data (Figure 7F). Collectively, these observations suggest that the heightened eosinophilia evoked by pAgs compared with sAgs is attributable to impairment in the endocytic trafficking of the $\mathrm{pAg} / \mathrm{IgE} / \mathrm{FccR}$ I complexes in MCs. The result is enhanced retention in lipid raft-enriched compartments that leads to sustained signaling reactions and enhanced mediator release from MCs as well as elevated pathological responses.

\section{Discussion}

The growing epidemic of exacerbated bronchial asthmatic symptoms has been associated with airborne particles $(3-5,7,8,42)$. Despite the particulate nature of many inhaled allergens, most in vivo and in vitro studies exploring the pathogenesis of allergic asthma continue to exclusively use soluble allergens in experimental models. Although there have been several studies aimed at investigating the health impact of ambient particles, they were either epidemiological studies to establish correlations of clinical asthma symptoms with certain types and amounts of environmental particulate pollutants, or toxicological studies to test host responses when exposed to collected environmental particles, such as diesel exhaust particles, road traffic particles, indoor particles, or pollens $(6,43-47)$. By using natural airborne particles with various compositions and bioactivities, these studies overlooked the potential pathologic effects of their common particulate attributes. Here, for the first time to our knowledge, we compared responses to sAgs and to the same amount of allergen associated on unisized polystyrene particles and found that eosinophilia induced by pAgs, regardless of the allergen type, resulted in significantly higher responses than those induced by sAgs in a mouse model of allergic asthma. Therefore, studies that exclusively use sAgs may not accurately model the development of the asthmatic phenotype. In our studies, we also elucidated a cellular basis for how pAgs evoke more robust inflammatory changes in the lung. We found that sensitized MC-sufficient mice responded differently to the physical nature of the allergen, with pAgs evoking significantly more eosinophilia responses than those induced by sAgs. Comparatively, pAg- and sAg-induced eosinophilia was also reduced in MC-deficient mice, which suggests that $\mathrm{MCs}$ are required for the full induction of eosinophilia. Howev$\mathrm{er}$, the presence of eosinophils in the BAL of these mice suggests that additional lung resident cell types may also contribute to the recruitment of these cells. Although MCs are well-known effectors in allergic disease, these findings suggested that MCs can differentially respond to the physical nature of an allergen and greatly augmented our understanding of the pathogenesis of asthma.

The differential responses of MCs to sAgs and pAgs was not attributable to qualitative differences in FceRI-mediated signaling following allergen engagement, an inference supported by the finding of similar signaling profiles of tyrosine-phosphorylated proteins and the observation that the degranulation responses to both sAgs and pAgs were comparable in magnitude. Instead, the almost 5-fold greater MC mediator responses to pAgs compared with sAgs was linked mechanistically to temporal and spatial aspects of IgE receptor-mediated signaling. After engagement of IgE/FceRI complexes by sAgs, signal transduction was short-lived and associated with the movement of the allergen-receptor complex through an endocytic route that sequentially involved $\mathrm{CD}^{+} 3^{+}$ compartments and the early Rab5 $5^{+}$endosome, followed by the late $\mathrm{Rab}^{+}$endosome and perhaps a degradative endosome/lysosome $(22,23,48)$. In contrast, after engagement of IgE/FceRI complexes by pAgs, signal transduction remained sustained and was related to the retention of these complexes in $\mathrm{CD} 3^{+}$compartments without further movement in the endocytic pathway. Because CD63 ${ }^{+}$ compartments are highly enriched in lipid rafts, which serve as an efficient platform for signal transduction, sustained signaling by $\mathrm{pAg} / \mathrm{IgE} / \mathrm{Fc \varepsilon RI}$ complexes could occur. In contrast, sAg-induced signaling was short-lived because sAg/IgE/FceRI complexes transited out of the $\mathrm{CD}^{+} 3^{+}$compartments into the endosomal/lysosomal pathways, where signaling was terminated as a result of degradation. It is noteworthy that sustained IgE signaling comparable to that evoked by pAgs could be induced by sAgs if its movement out of $\mathrm{CD} 3^{+}$compartments was purposely impeded, either through pharmacological agents that block endocytosis or by deletion of specific molecules required for this process. Several models have previously reported that retarding endocytosis of IgE/FceRI complexes - through deletion of RabGEF1/Rabex-5, a guanosine nucleotide exchange factor (49), or by using cytochalasin D or latrunculin to block actin polymerization $(38,50)$ - resulted in elevated FceRI signaling and production of specific cytokines by MCs. Similarly, accelerating the sorting of IgE/FceRI complexes into early endosome/lysosomes by overexpression of CIN85, a molecule that regulates IgE/FceRI endocytosis, resulted in attenuated FceRI signaling $(21,51)$. These prior studies, together with our current findings, highlight the largely overlooked role of MC endocytic circuitry and the intracellular location of these activities in regulating duration of mediator responses to allergens.

Recent studies have shown that the endosomal system can serve not only as a conduit for the degradation and recycling of cell surface receptors, but also as an essential site where receptor signaling can be initiated, sustained, and terminated (52). In our studies, we demonstrated that whereas sAgs were rapidly trafficked through the degradative endocytic pathway, and IgE/FceRI complex-mediated signaling was quickly terminated, retention 
of IgE/FceRI complexes in the nondegradative lipid raft-containing compartment by pAgs vastly enhanced IgE/FceRI complex-mediated signaling, proinflammatory cytokine production, and airway allergic responses. The robust interferon responses of plasmacytoid dendritic cells to $\mathrm{CPG}$ have similarly been linked to selective retention of TLR9/MyD88/IRF-7 signaling complexes for long periods within endosomes (53). Our present data give additional evidence that the signaling emanating from early endocytic structures can control key functional aspects of cells and lead to critical physiological outcomes. The molecular mechanisms of how pAg/IgE/FceRI complexes avoid rapid degradative fate and signaling termination are currently unknown. They may be regulated by the rate of ligand dissociation, as suggested by the studies on EGFR- and GPCR-mediated endosomal signaling. Alternatively, this effect may be related to differential activation of specific signaling components, including Cbl-b or RabGEF1, which contribute to the ubiquitination process and degradation of FceRI $(49,54)$.

There is still no explanation of why pAgs escape degradation and are harbored in specialized lipid raft-enriched secretory granule-like compartments for prolonged periods of time. Perhaps the disassociation rate of allergen with IgE/FcERI complexes in these distinct compartments influences their sorting into the endosome/lysosome pathway. Although both sAgs and pAgs consist of the same allergen protein with the same affinity to IgE/FceRI complexes, the physical nature of pAgs might enable them to bind more receptors, resulting in higher antigen avidity and a slower disassociation rate. As previously reported, the disassociation rate of ligand and receptor can influence the sorting of the receptor into the endocytic system (52). In this respect, the slower disassociation rate of pAgs with IgE/FceRI complexes might result in markedly delayed passage into degradative endosomal networks. A second possibility might be that large clustered regions of lipid rafts aggregated around pAgs may exclude certain important molecules to trigger the sorting process, such as ubiquitin ligases or other adaptor molecules responsible for ubiquitination of FcERI $(21,54)$, or molecules to connect or coordinate the movement of actin or microtubule cytoskeletons (37, 50). The last possible explanation for the prolonged presence of particulate allergens in granules may be the inherent incapability of MCs to exocytose and process particulate cargo. Unlike macrophages or neutrophils, which are functionally specialized to phagocytose various agents, including particulate pathogens, MCs are primarily secretory cells.

Another potential explanation for prolonged signaling by pAgs from within MCs involves lipid rafts. These structures are unique plasma membrane microdomains enriched in cholesterol and sphingolipids and have been demonstrated to be important in initiation of FceRI signaling $(29,55)$ in MCs. A recent study showed that lipid rafts create a protective environment that maintains the activity of the FceRI-activated kinase Lyn (56). In this study, we examined the dynamics of FceRI-initiated signaling in lipid rafts and found that sAg-induced localization of FceRI and its downstream phosphorylated signal molecules within lipid rafts only lasted for a short time of 10 minutes. This finding is identical to that of a previous study showing that sAg-induced coalescence of crosslinked FceRI within lipid rafts was transient and markedly decreased 10 minutes after activation (57). Moreover, by comparing the dynamic location of FceRI and downstream tyrosine phosphorylation events within lipid rafts after exposure to sAgs or
pAgs, we found that, in contrast to sAgs, pAgs induced prolonged colocalization of crosslinked FceRI and phosphorylated signaling events within lipid rafts of MCs. This may be because interactions among FceRI and its downstream tyrosine kinases were better preserved in pAg-induced lipid raft clusters, and therefore the activated signaling was maintained for longer lengths of time. In summary, our observations suggest that the coalescence of FceRI in lipid rafts is not only important for initiation of signaling, but also crucial for maintenance of activated signaling.

Our findings reaffirmed the central role of MCs as effector cells in a mouse model of allergic asthma and revealed a powerful mechanism for how particulate environmental allergens exacerbate pulmonary function and inflammatory responses. These findings, in concert with recent observations that IgE-sensitized MCs retain naturally particulate allergens without degradation for extended periods of time (25), suggest a scenario in which pulmonary MCs mediate sustained signaling for extended periods of time after exposure to pAgs. This model may be supported by observations in asthmatic patients, in which MCs exhibit a chronically activated phenotype, even after exposure of the patient to the offending allergen has been eliminated (13). Given our present demonstration that prolongation of MC signaling by pAgs occurred through delayed endocytosis of IgE/FceRI complexes, pharmacological agents that target and destabilize endosomes or accelerate MC endocytotic activity may be promising new therapies for allergic asthma.

\section{Methods}

Animals and MC reconstitutions. Male 6- to 8-week-old C57BL/6 mice were purchased from the NCI-Frederick Animal Production Area. Male MC-deficient Wsh mice $\left(K i t^{W-s h} / K i t^{W-s h}\right)$ on a C57BL/6 background (Jackson Laboratories) were bred at the Duke University vivarium. Caveolin-deficient Cav1 $1^{\mathrm{tm} 1 \mathrm{M} 1 \mathrm{~s} / \mathrm{J}}$ mice $\left(\mathrm{Cav}^{-/-}\right)$and congenic littermate control B6129SF2/J mice $\left(\mathrm{Cav}^{+/+}\right)$were a gift from J.R. Wright (Duke University). All strains were housed in the Duke University vivarium and provided food and water ad libitum. BMMCs were obtained by culturing bone marrow from the indicated mice for 4 weeks in RPMI medium containing 10\% FBS, $100 \mathrm{U} / \mathrm{ml}$ penicillin/streptomycin, $25 \mathrm{mM}$ HEPES, $2 \mathrm{mM}$ L-glutamine, $1 \mathrm{mM}$ sodium pyruvate, $1 \mathrm{mM}$ nonessential amino acids, $1 \mathrm{mM}$ MEM amino acids (all from Invitrogen), $5 \mathrm{ng} / \mathrm{ml} \mathrm{IL-3,} \mathrm{and} 5 \mathrm{ng} / \mathrm{ml} \mathrm{SCF}$ (R\&D Systems). BMMC phenotype was confirmed by flow cytometry $\left(\mathrm{Kit}^{+}, \mathrm{Fc \varepsilon RI}{ }^{+}\right)$and histochemical staining with Toluidine Blue (EM Science). To reconstitute Wsh mice with MCs, 6-week-old Wsh mice were replenished with $1 \times 10^{7}$ BMMCs per mouse through retro-orbital injection and allowed to recover for 6-8 weeks prior to experimentation. Analysis of reconstitution efficiency revealed that BMMCs were efficiently reconstituted in lungs of Wsh mice and were found in the bronchial and alveolar regions of the lung (Supplemental Figure 1 and Supplemental Table 1). Comparable numbers of MCs were found in the lungs of Wsh mice reconstituted with $\mathrm{Cav}^{-/-}$and $\mathrm{Cav}^{+/+} \mathrm{BMMCs}$ (Supplemental Table 1$)$. However, as previously reported $(58,59)$, the total number of MCs in reconstituted lungs of Wsh mice was elevated relative to the number in WT mouse lungs. This elevated number might be explained by the observation that there were more MCs deposited throughout the alveolar sites as a result of the enriched blood supply in this area (data not shown). All experiments were performed with protocols approved by the Duke Division of Laboratory Animal Resources and the Duke University Institutional Animal Care and Use Committee.

$s A g$ and pAg preparation. HDM extract (Greer Lab), RW extract (Greer Lab), and OVA/TNP (Biosearch Technologies) sAgs were purchased with accurate protein quantification. pAgs were prepared by covalently conjugating 
$1 \mu \mathrm{m}$ Polybead carboxylate polystyrene microspheres (Polysciences) to natural allergen extracts or OVA/TNP using the Polylink protein coupling kit for carboxylate microspheres (Polysciences). The amount of natural allergens or OVA/TNP conjugated on beads was directly quantified by BCA protein assay kit (Pierce) on NanoDrop Spectrophotometer. Unless otherwise indicated, the concentration of OVA/TNP conjugated on microsphere cores was $1 \mu \mathrm{g}$ per $10^{7}$ beads. Both sAg and pAg preparations contained very little LPS, as determined by Limulus assay. The amounts were approximately $0.7 \mathrm{EU}$ per $\mu \mathrm{g}$ (approximately $0.7 \mathrm{pg}$ LPS) of each allergen preparation, levels well below the amounts required to activate MCs or trigger primary allergic responses in the lung (refs. 60-62 and data not shown). Analysis of pAg characteristics showed that pAg prepared by the covalent conjugation of OVA/TNP on particles was very stable, as OVA/TNP pAg did not release detectable amounts of protein in either acidic or physiological neutral environments (ref. 63 and data not shown).

Active sensitization and airway challenge of mice. To induce allergen-specific $\mathrm{IgE}$, mice were injected with $50 \mu \mathrm{g}$ allergen protein into the peritoneal cavity 7 times on alternate days. This procedure was found to induce total and antigen-specific IgE and IgG1 levels that were comparable in all strains of mice, including MC-deficient and -sufficient mice (data not shown). On day 36 , mice were challenged with saline, sAgs, pAgs, or blank particles. To perform the airway challenge, mice were anesthetized with ketamine mixed with xylaxine and hung against an angled stand. Allergens were then instilled through the trachea and nares in $60 \mu \mathrm{l}$ and $20 \mu \mathrm{l}$ saline, respectively. For HDM and RW sAgs or pAgs, $50 \mu \mathrm{g}$ and $10 \mu \mathrm{g}$ of allergens were instilled into trachea and nares, respectively. For challenges with OVA/TNP sAgs or pAgs, $160 \mu \mathrm{g}$ and $40 \mu \mathrm{g}$ of either allergen was instilled into trachea and nares, respectively. At 48 hours after the challenge, mice were subjected to subsequent analysis of lung pathology.

$B A L$ and lung histology. To perform lavage, mice were sacrificed, and the tracheas were cannulated. To obtain BAL cells, $1 \mathrm{ml}$ HBSS (Gibco; Invitrogen) with $10 \mathrm{mM}$ EDTA (Sigma-Aldrich) was instilled into the lung 3 times. BAL cells were then cytospun onto slides, fixed in 1:1 mixed acetone and methanol, and stained with H\&E. Total cells were counted by hemocytometer. Differential cell populations in BAL fluids were evaluated based on their morphology, and eosinophils were the only cells specifically elevated by pAgs (Supplemental Figure 2). For lung histology, $5-\mu \mathrm{M}$-thick paraffin-embedded lung tissues were cut and stained with H\&E. Eosinophils in lungs were quantified according to area in square millimeters. NIH Image J software was used to scale tissue area in the captured images. Eosinophil number was expressed as the total number of eosinophils counted per tissue area.

In vitro sensitization and challenge of BMMCs. Sensitization of BMMCs in vitro was performed by incubating $1 \times 10^{6}$ cells with $0.5 \mu \mathrm{g}$ mouse antiTNP IgE (BD Biosciences - Pharmingen). After incubation for 18 hours, cells were washed 3 times with RPMI to remove unbound IgE. After washing, cells were incubated in growth media at $37^{\circ} \mathrm{C}$ for 2 hours to allow recovering from washing stimulus. The sensitized BMMCs were then challenged with $1 \mu \mathrm{g}$ OVA/TNP in sAg form or $1 \mu \mathrm{g}$ OVA/TNP pAg (associated on particles). Cells were collected at the indicated times for analysis.

Hexosaminidase assay. 1 hour after the allergen exposure to BMMCs, the enzymatic activities of $\beta$-hexosaminidase in supernatants and cell pellets of $1 \times 10^{6}$ cells were detected. The enzyme activity in Tyrode's buffer was measured with $p$-nitrophenol- $N$-acetyl- $\alpha$-D-glucosaminide in $0.1 \mathrm{M}$ sodium citrate ( $\mathrm{pH} 4.5$ ) for 1 hour at $37^{\circ} \mathrm{C}$. The reaction was stopped by the addition of $0.1 \mathrm{M}$ carbonate buffer $(\mathrm{pH} 10.0)$. The release of the product 4 -p-nitrophenol was detected by absorbance at $405 \mathrm{~nm}$. The extent of degranulation was calculated by dividing 4-p-nitrophenol absorbance in the supernatant by the sum of absorbance in the supernatant and in the cell pellet solubilized in $0.1 \%$ Triton X-100.
RNA isolation and real-time PCR to test mRNA of cytokines and chemokines. At the indicated times, total RNA was isolated from $1 \times 10^{6} \mathrm{BMMCs}$ using the RNeasy Kit (Qiagen). cDNA was synthesized using the iScript cDNA synthesis kit (BioRad). Real-time PCR was performed using the iQ SYBR Green Supermix (BioRad), and data were acquired on an iCycler real-time PCR machine (BioRad). The expression of cytokines and chemokines was normalized to actin expression. The expression in each challenging group was further standardized to the untreated control group. Primers were synthesized by Integrated DNA Technologies. Primer sequences are as follows: actin, forward 5'-GATTACTGCTCTGGCTCCTAGC-3', reverse 5'-GACTCATCGTACTCCTGCTTGC-3'; IL-4, forward 5'-TCCTCACAGCAACGAAGAACACCA-3', reverse 5'-GCAGCTTATCGATGAATCCAGGCA-3'; IL-5, forward 5'-CTCTGTTGACAAGCAATGAGACG-3', reverse 5'-TCTTCAGTATGTCTAGCCCCTG-3'; IL-13, forward 5'-AGACCAGACTCCCCTGTGCA-3', reverse $5^{\prime}$-TGGGTCCTGTAGATGGCATTG-3'; TNF- $\alpha$, forward $5^{\prime}$-TCTCATGCACCACCATCAAGGACT- ${ }^{\prime}$, reverse $5^{\prime}$-ACCACTCTCCCTTTGCAGAACTCA-3'; eotaxin-1, forward 5'-TCAAGACCAGGTTGGGCAAAGAGA-3', reverse 5'-TCAAGCAGTTCTTAGGCTCTGGGT-3'.

Western blots of total cellular tyrosine phosphorylation. At the indicated times, $1 \times 10^{6}$ BMMCs were pelleted and lysed in RIPA lysis buffer (Upstate Biotechnology) with $1 \mathrm{mM}$ phenylmethylsulfonyl fluoride (Sigma-Aldrich), $1 \%$ protease inhibitor cocktail (Sigma-Aldrich), and 1\% phosphatase inhibitor cocktail (Sigma-Aldrich). Cell lysates were incubated on ice for 30 minutes and then centrifuged at $17,000 \mathrm{~g}$ for 10 minutes. Supernatant was collected, and total protein was quantified using a BCA protein assay kit. Cell lysates were normalized for protein amount and volume. Proteins were denatured by boiling for 5 minutes in $2 \times$ Lammeli sample buffer (BioRad) with $0.05 \% \beta$-mercaptoethanol (Sigma-Aldrich). Protein samples were resolved by SDS-PAGE and transferred to nitrocellulose membranes. Tyrosine-phosphorylated proteins were probed using primary anti-phosphotyrosine monoclonal antibody 4G10 (gift of W. Zhang, Duke University) and detected with a secondary HRP-linked anti-mouse antibody and the Super Signal West Pico Chemiluminescent kit (Pierce). The intensity of phosphorylation of prominent protein bands was assessed with Image J software. The normalized density of the bands was determined using actin as the internal quantitative control.

Construction of GFP fusion protein-transfected BMMCs. Total RNA was prepared from BMMCs. cDNA for CD63, Rab5, and Rab7 genes were generated by RT-PCR using the following primer sequences: CD63, forward 5'-CTCAGATCTCATGGCGGTGGAAGGAGGAATGA-3', reverse 5'-CTCGGGCCCGCATTACTTCATAGCCACTTCGA-3'; Rab5, forward 5'-CTCAGATCTATGGCTAATCGAGGAGCAACAAGA-3', reverse 5'-CTCGGATCCTCAGTTACTACAACACTGGCTTC-3'; Rab7, forward 5'-GATCTCGAGCTATGACCTCTAGGAAGAAAGTGTTG-3', reverse 5'-GTCGGGCCCGCTCAACAACTGCAGCTTTCTGCG-3'. The PCR product of CD63 was restriction enzyme digested and ligated in-frame into the PLEGFP-N1 vector (BD Biosciences) to generate PGFP-CD63. The PCR products of Rab5 and Rab7 were restriction enzyme digested and ligated in-frame into the PLEGFP-C1 vector (BD Biosciences) to generate PGFP-R5 and PGFP-R7, respectively. Sequence accuracy was confirmed by sequencing. Generation of infectious viral particles, viral transfection, and selection of transfected BMMCs were performed as recommended by the vendor (BD Biosciences).

Fluorescent prelabeling of allergens and IgE. sAg (OVA/TNP) was prelabeled with an Alexa Fluor protein labeling kit (Invitrogen). pAg (OVA/TNP conjugated beads) was prelabeled with the Alexa Fluor carboxylic acid succinimidyl ester (Invitrogen). Anti-TNP IgE (BD Biosciences - Pharmingen) was prelabeled with an Alexa Fluor monoclonal antibody labeling kit (Invitrogen).

Confocal microscopy to examine localization within lipid raft compartments. BMMCs were sensitized by Alexa Fluor 546-prelabeled IgE and then challenged by Alexa Fluor 488-prelabeled pAgs or sAgs as described above. At 
the indicated times, cells were collected and fixed in $4 \%$ paraformaldehyde (Sigma-Aldrich). Cells were then permeated in $0.15 \%$ saponin (Sigma-Aldrich) in PBS containing 1\% FBS (Invitrogen) and probed with Alexa Fluor 647-conjugated cholera toxin subunit B (Invitrogen) for 30 minutes on ice to detect lipid rafts. Cells were washed 3 times with saponin buffer, followed by a wash in PBS, and then placed onto slides and air dried. Slides were sealed with Pro-Long antifade reagent (Invitrogen). Confocal images of cells were obtained using a Plan Fluor 100x oil objective and Nikon ECLIPSE TE200 microscope (Nikon). EZ-C1 Nikon software (Silver Version 2.01) with a channel-series approach was used to prevent spectral overlap between fluorescent signals.

Lipid raft fractionation. For each challenge group, $1 \times 10^{7} \mathrm{BMMCs}$ were pelleted and resuspended in $2 \mathrm{ml}$ of ice-cold 2-[N-morpholino]ethanesulfonic acid (MES) buffer (25 mM MES, $150 \mathrm{mM} \mathrm{NaCl}$, pH 6.5) with $0.2 \%$ Triton $\mathrm{X}-100,1 \%$ protease inhibitor cocktail, $1 \%$ phosphatase inhibitor cocktail, $1 \mathrm{mM}$ PMSF, and $5 \mathrm{mM}$ EDTA (all from Sigma-Aldrich) for 30 minutes on ice. Each sample was then mixed with an equal volume of $90 \%$ sucrose in MES to bring to $4 \mathrm{ml}$ of $45 \%$ sucrose solution, and then overlaid with $4 \mathrm{ml}$ each of $35 \%$ and $5 \%$ sucrose in MES. The gradients were centrifuged for 18 hours at 187,000 $\mathrm{g}$ in a SW41Ti rotor (Beckman Instruments). 12 $1-\mathrm{ml}$ cell fractions were collected from the top of the gradient, diluted in $2 \times$ Laemmli sample buffer (Bio-Rad) with $0.05 \% \beta$-mercaptoethanol (Sigma-Aldrich), and boiled for 5 minutes. Western blot was performed to detect the distribution of the FceRI- $\gamma$ chain in cell fractions using polyclonal anti-FceRI- $\gamma$ subunit (Upstate). Flotillin, a lipid raft marker, was detected by anti-flotillin (clone H-104; Santa Cruz). In some assays, lipid raft fractions 4 and 5 were pooled to exclusively test the FceRI- $\gamma$ chain and tyrosine phosphorylation signaling in lipid rafts.

1. Sugita M, Kuribayashi K, Nakagomi T, Miyata S, Matsuyama T, Kitada O. Allergic bronchial asthma: airway inflammation and hyperresponsiveness. Intern Med. 2003;42(8):636-643.

2. Cohn L, Elias JA, Chupp GL. Asthma: mechanisms of disease persistence and progression. Annu Rev Immunol. 2004;22:789-815.

3. Braman SS. The global burden of asthma. Chest. 2006;130(1 suppl):4S-12S.

4. Downs SH, et al. Reduced exposure to PM10 and attenuated age-related decline in lung function. NEngl J Med. 2007;357(23):2338-2347.

5 . McCreanor J, et al. Respiratory effects of exposure to diesel traffic in persons with asthma. $N$ Engl J Med. 2007;357(23):2348-2358.

6. Granum B, Lovik M. The effect of particles on allergic immune responses. Toxicol Sci. 2002;65(1):7-17.

7. D'Amato G, Liccardi G, D'Amato M, Holgate S. Environmental risk factors and allergic bronchial asthma. Clin Exp Allergy. 2005;35(9):1113-1124.

8. Ormstad H, Johansen BV, Gaarder PI. Airborne house dust particles and diesel exhaust particles as allergen carriers. Clin Exp Allergy. 1998;28(6):702-708.

9. Ormstad H. Suspended particulate matter in indoor air: adjuvants and allergen carriers. Toxicology. 2000;152(1-3):53-68.

10. Seaton A, MacNee W, Donaldson K, Godden D. Particulate air pollution and acute health effects. Lancet. 1995;345(8943):176-178.

11. Kay AB. The role of eosinophils in the pathogenesis of asthma. Trends Mol Med. 2005;11(4):148-152.

12. Galli SJ, Tsai M, Piliponsky AM. The development of allergic inflammation. Nature. 2008; 454(7203):445-454.

13. Bradding P, Walls AF, Holgate ST. The role of the mast cell in the pathophysiology of asthma. J Allergy Clin Immunol. 2006;117(6):1277-1284.

14. Hellings PW, Ceuppens JL. Mouse models of global airway allergy: what have we learned and what should we do next? Allergy. 2004;59(9):914-919.

15. Kurosaki T, Gander I, Wirthmueller U, Ravetch JV.
Statistics. Data were analyzed for statistical significance using 1-way ANOVA (GraphPad Prism). Data were presented as mean $\pm \mathrm{SD}$, and a $P$ value less than 0.05 was considered significant.

\section{Acknowledgments}

We thank J.R. Wright for Cav $v^{-/}$and $\mathrm{Cav}^{+/+}$mice; W.G. Zhang for the 4G10 antibody; M.E. Sunday for the use of microscopes; J.Y. Ning for pathology assistance and helpful discussion; and A.L. St. John, A.M. Hofmann, S.E. Bowen, and W.X.G. Ang for critical comments relating to the manuscript. IVIS animal imaging was performed in the NIAID Regional Biocontainment Laboratory at Duke University (UC6-AI058607, U54-AI057157, and P30-AI051445) by the Duke Human Vaccine Institute Biocontainment Animal Imaging Shared Resource Facility. This work was funded by NIH grants AI081672, ES016347, AI056101, AI150021, AI074751, DK077307, DK077159, and DK050814. S.N. Abraham was supported by a Senior Fellowship from the American Asthma Foundation.

Received for publication May 3, 2010, and accepted in revised form December 1, 2010.

Address correspondence to: Soman N. Abraham, Department of Pathology, Duke University Medical Center, Box 3712, Durham, North Carolina 27514, USA. Phone: 919.684.3630; Fax: 919.684.2021; E-mail: soman.abraham@duke.edu.

Cong Jin's present address is: Institute for Viral Disease Control and Prevention, Center for Disease Control, Beijing, China.
The beta subunit of the Fc epsilon RI is associated with the Fc gamma RIII on mast cells. J Exp Med. 1992;175(2):447-451.

16. Daeron M, Malbec O, Latour S, Arock M, Fridman WH. Regulation of high-affinity IgE receptor-mediated mast cell activation by murine low-affinity IgG receptors. J Clin Invest. 1995;95(2):577-585.

17. Nakae S, et al. Mast cell-derived TNF contributes to airway hyperreactivity, inflammation, and TH2 cytokine production in an asthma model in mice. J Allergy Clin Immunol. 2007;120(1):48-55.

18. Brightling CE, Symon FA, Holgate ST, Wardlaw AJ, Pavord ID, Bradding P. Interleukin- 4 and -13 expression is co-localized to mast cells within the airway smooth muscle in asthma. Clin Exp Allergy. 2003; 33(12):1711-1716.

19. Mould AW, Ramsay AJ, Matthaei KI, Young IG, Rothenberg ME, Foster PS. The effect of IL- 5 and eotaxin expression in the lung on eosinophil trafficking and degranulation and the induction of bronchial hyperreactivity. J Immunol. 2000;164(4):2142-2150.

20. Isersky C, Rivera J, Segal DM, Triche T. The fate of IgE bound to rat basophilic leukemia cells. II. Endocytosis of $\operatorname{IgE}$ oligomers and effect on receptor turnover. J Immunol. 1983;131(1):388-396.

21. Molfetta R, et al. CIN85 regulates the ligand-dependent endocytosis of the IgE receptor: a new molecular mechanism to dampen mast cell function. J Immunol. 2005;175(7):4208-4216.

22. Zerial M, McBride H. Rab proteins as membrane organizers. Nat Rev Mol Cell Biol. 2001;2(2):107-117.

23. Bucci C, Thomsen P, Nicoziani P, McCarthy J, van Deurs B. Rab7: a key to lysosome biogenesis. $\mathrm{Mol}$ Biol Cell. 2000;11(2):467-480.

24. Wu M, Baumgart T, Hammond S, Holowka D, Baird B. Differential targeting of secretory lysosomes and recycling endosomes in mast cells revealed by patterned antigen arrays. J Cell Sci. 2007; 120(pt 17):3147-3154.

25. Shin JS, Shelburne CP, Jin C, LeFurgey EA, Abraham SN. Harboring of particulate allergens within secretory compartments by mast cells following IgE/FcepsilonRI-lipid raft-mediated phagocytosis. J Immunol. 2006;177(9):5791-5800.

26. Galbiati F, Razani B, Lisanti MP. Emerging themes in lipid rafts and caveolae. Cell. 2001;106(4):403-411.

27. Brown DA, London E. Functions of lipid rafts in biological membranes. Annu Rev Cell Dev Biol. 1998; 14:111-136.

28. Anderson RG, Jacobson K. A role for lipid shells in targeting proteins to caveolae, rafts, and other lipid domains. Science. 2002;296(5574):1821-1825.

29. Wilson BS, Pfeiffer JR, Oliver JM. FcepsilonRI signaling observed from the inside of the mast cell membrane. Mol Immunol. 2002;38(16-18):1259-1268.

30. Holowka D, et al. Lipid segregation and IgE receptor signaling: a decade of progress. Biochim Biophys Acta. 2005;1746(3):252-259.

31. Sheets ED, Holowka D, Baird B. Critical role for cholesterol in Lyn-mediated tyrosine phosphorylation of FcepsilonRI and their association with detergent-resistant membranes. J Cell Biol. 1999; 145(4):877-887.

32. Frankel DJ, et al. Revealing the topography of cellular membrane domains by combined atomic force microscopy/fluorescence imaging. Biophys J. 2006; 90(7):2404-2413.

33. Fattakhova G, Masilamani M, Borrego F, Gilfillan AM, Metcalfe DD, Coligan JE. The highaffinity immunoglobulin-E receptor (Fcepsilon$\mathrm{RI}$ ) is endocytosed by an AP-2/clathrin-independent, dynamin-dependent mechanism. Traffic. 2006;7(6):673-685.

34. Mao SY, Pfeiffer JR, Oliver JM, Metzger H. Effects of subunit mutation on the localization to coated pits and internalization of cross-linked IgE-receptor complexes. J Immunol. 1993;151(5):2760-2774.

35. Merrifield CJ, et al. Endocytic vesicles move at the tips of actin tails in cultured mast cells. Nat Cell Biol. 1999;1(1):72-74.

36. Mayor S, Pagano RE. Pathways of clathrin-independent endocytosis. Nat Rev Mol Cell Biol. 2007; 
8(8):603-612.

37. Andrews NL, et al. Actin restricts FcepsilonRI diffusion and facilitates antigen-induced receptor immobilization. Nat Cell Biol. 2008;10(8):955-963.

38. Frigeri L, Apgar JR. The role of actin microfilaments in the down-regulation of the degranulation response in RBL-2H3 mast cells. J Immunol. 1999; 162(4):2243-2250.

39. Nabi IR, Le PU. Caveolae/raft-dependent endocytosis. J Cell Biol. 2003;161(4):673-677.

40. Schubert W, Frank PG, Razani B, Park DS, Chow CW, Lisanti MP. Caveolae-deficient endothelial cells show defects in the uptake and transport of albumin in vivo. J Biol Chem. 2001;276(52):48619-48622.

41. Anderson RG. Caveolae: where incoming and outgoing messengers meet. Proc Natl Acad Sci U S A. 1993; 90(23):10909-10913.

42. Bernstein JA, et al. Health effects of air pollution. J Allergy Clin Immunol. 2004;114(5):1116-1123.

43. Hao M, Comier S, Wang M, Lee JJ, Nel A. Diesel exhaust particles exert acute effects on airway inflammation and function in murine allergen provocation models. J Allergy Clin Immunol. 2003;112(5):905-914.

44. Nel AE, Diaz-Sanchez D, Ng D, Hiura T, Saxon A. Enhancement of allergic inflammation by the interaction between diesel exhaust particles and the immune system. J Allergy Clin Immunol. 1998; 102(4 pt 1):539-554.

45. Schaumann F, et al. Metal-rich ambient particles (particulate matter 2.5) cause airway inflammation in healthy subjects. Am J Respir Crit Care Med. 2004; 170(8):898-903.

46. Schwartz J, Neas LM. Fine particles are more strongly associated than coarse particles with acute respiratory health effects in schoolchildren. Epidemiology. 2000;11(1):6-10.

47. Gaffin JM, Phipatanakul W. The role of indoor allergens in the development of asthma. Curr Opin Allergy Clin Immunol. 2009;9(2):128-135.

48. Feng Y, Press B, Wandinger-Ness A. Rab 7: an important regulator of late endocytic membrane traffic. J Cell Biol. 1995;131(6 pt 1):1435-1452.

49. Kalesnikoff J, et al. Roles of RabGEF1/Rabex5 domains in regulating Fc epsilon RI surface expression and Fc epsilon RI-dependent responses in mast cells. Blood. 2007;109(12):5308-5317.

50. Holowka D, Sheets ED, Baird B. Interactions between $\mathrm{Fc}$ (epsilon)RI and lipid raft components are regulated by the actin cytoskeleton. J Cell Sci. 2000;113(pt 6):1009-1019.

51. Peruzzi G, et al. The adaptor molecule CIN85 regulates Syk tyrosine kinase level by activating the ubiquitin-proteasome degradation pathway. J Immunol. 2007;179(4):2089-2096.

52. Murphy JE, Padilla BE, Hasdemir B, Cottrell GS, Bunnett NW. Endosomes: a legitimate platform for the signaling train. Proc Natl Acad Sci U S A. 2009; 106(42):17615-17622.

53. Honda K, et al. Spatiotemporal regulation of MyD88-IRF-7 signalling for robust type-I interferon induction. Nature. 2005;434(7036):1035-1040.

54. Gustin SE, Thien CB, Langdon WY. Cbl-b is a negative regulator of inflammatory cytokines produced by IgE-activated mast cells. J Immunol. 2006; 177(9):5980-5989.

55. Draber P, Draberova L. Lipid rafts in mast cell sig- naling. Mol Immunol. 2002;38(16-18):1247-1252.

56. Young RM, Holowka D, Baird B. A lipid raft environment enhances Lyn kinase activity by protecting the active site tyrosine from dephosphorylation. J Biol Chem. 2003;278(23):20746-20752.

57. Stauffer TP, Meyer T. Compartmentalized IgE receptor-mediated signal transduction in living cells. J Cell Biol. 1997;139(6):1447-1454.

58. Grimbaldeston MA, Chen CC, Piliponsky AM, Tsai M, Tam SY, Galli SJ. Mast cell-deficient W-sash c-kit mutant Kit W-sh/W-sh mice as a model for investigating mast cell biology in vivo. Am J Pathol. 2005; 167(3):835-848.

59. Martin TR, Takeishi T, Katz HR, Austen KF, Drazen JM, Galli SJ. Mast cell activation enhances airway responsiveness to methacholine in the mouse. J Clin Invest. 1993;91(3):1176-1182.

60. Delayre-Orthez C, de Blay F, Frossard N, Pons F. Dose-dependent effects of endotoxins on allergen sensitization and challenge in the mouse. Clin Exp Allergy. 2004;34(11):1789-1795.

61. Eisenbarth SC, Piggott DA, Huleatt JW, Visintin I, Herrick CA, Bottomly K. Lipopolysaccharide-enhanced, toll-like receptor 4-dependent $\mathrm{T}$ helper cell type 2 responses to inhaled antigen. J Exp Med. 2002;196(12):1645-1651.

62. Supajatura V, Ushio H, Nakao A, Okumura K, Ra C, Ogawa H. Protective roles of mast cells against enterobacterial infection are mediated by Toll-like receptor 4. J Immunol. 2001;167(4):2250-2256.

63. Hunt JF, et al. Endogenous airway acidification. Implications for asthma pathophysiology. Am J Respir Crit Care Med. 2000;161(3 pt 1):694-699. 